\title{
A Structural, Spectroscopic and Computational Examination of the Dative Interaction in Constrained Phosphine-Stibines and Phosphine-Stiboranes
}

Brian A. Chalmers, Michael Bühl, Kasun S. Athukorala Arachchige, Alexandra M. Z. Slawin, Petr Kilian*

Brian A. Chalmers, Professor Michael Bühl, Dr. Kasun S. Athukorala Arachchige, Professor Alexandra M. Z. Slawin, Dr. Petr Kilian

EaStChem School of Chemistry, University of St Andrews

Corresponding author: EaStChem School of Chemistry, University of St Andrews, St Andrews, Fife KY16 9ST, UK. Email pk7@st-andrews.ac.uk

Supporting information for this article is available on the WWW under http://dx.doi.org/10.1002/chem.2014xxxxx.

\begin{abstract}
A series of phosphine-stibine and phosphine-stiborane peri-substituted acenaphthenes containing all permutations of pentavalent groups $-\mathrm{SbCl}_{\mathrm{n}} \mathrm{Ph}_{4-\mathrm{n}}(\mathbf{5 - 9})$, as well as trivalent groups $-\mathrm{SbCl}_{2},-\mathrm{Sb}(\mathrm{R}) \mathrm{Cl}$, and $-\mathrm{SbPh}_{2}(\mathbf{2}-\mathbf{4}, \mathrm{R}=\mathrm{Ph}, \mathrm{Mes})$, were synthesised and fully characterised including single crystal diffraction and multinuclear NMR. In addition, the bonding in these species was studied by DFT computational methods. The P-Sb dative interactions in both series range from strongly bonding to non-bonding as the Lewis acidity of the $\mathrm{Sb}$ acceptor is decreased. In the pentavalent antimony series, a significant change in the $\mathrm{P}-\mathrm{Sb}$ distance is observed between $-\mathrm{SbClPh}_{3}$ and $-\mathrm{SbCl}_{2} \mathrm{Ph}_{2}$ derivatives 6 and 7, consistent with a change from a bonding to a non-bonding interaction in a response to relatively small change in Lewis acidity of the acceptor. In the $\mathrm{Sb}^{\mathrm{III}}$ series, two geometric forms are observed. The $\mathrm{P}-\mathrm{Sb}$ bond length in the $\mathrm{SbCl}_{2}$ derivative $\mathbf{2}$ is as expected for a normal (rather than a dative) bond. Rather unexpectedly, the phosphine-stiborane complexes 5-9 represent the first examples of $\sigma^{4} \mathrm{P} \rightarrow \sigma^{6} \mathrm{Sb}$ structural motif.
\end{abstract}




\section{Introduction}

Stabilisation of main group motifs through Lewis base coordination is one of the prominent

topics of contemporary p-block chemistry, ${ }^{[1]}$ and while the fundamental bonding aspects in dative species have been under scrutiny for several decades, some intense discussions have been ongoing very recently. ${ }^{[2]}$ Apart from N-heterocyclic carbenes, phosphines remain a popular choice amongst Lewis bases in such species due to their favourable electronic properties (strong $\sigma$-donors and $\pi$-acceptors, which are widely tunable). ${ }^{[3]}$

In connection with our investigations into the chemistry of peri-substituted naphthalenes, ${ }^{[4]}$ we have established a long-term interest in backbone supported dative species with Group 15 atoms acting as both donors and acceptors. Halophosphines are sufficiently electrophilic to act as (lone pair possessing) acceptors to other phosphines, although thermally stable examples of this are rather rare as such species generally disproportionate at or below ambient temperature. Phosphine-phosphine donor-acceptor complexes adopt either a monomeric structure with pseudo-tbp (trigonal bipyramidal) coordination of the acceptor $\mathbf{P}$ atom (A and $\mathbf{D}$ in Figure 1); or a dimeric structure with pseudo-octahedral coordination of the acceptor $\mathrm{P}$ atom $(\mathbf{C}$ in Figure 1$){ }^{[5]}$ 


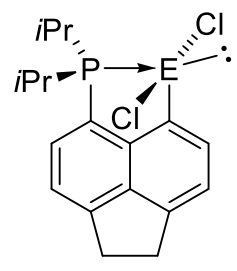

A: $E=P$

B: $E=A s$

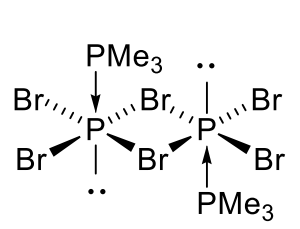

C

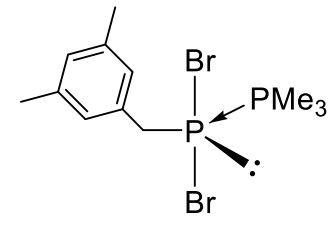

D<smiles>C[14C]1([14CH3])c2cccc3cccc(c23)[Se]1(Cl)Cl</smiles><smiles>CN1c2cccc3cccc(c23)[B-]1(Cl)c1cccc2cccc([N+](C)(C)C)c12</smiles><smiles>C[N+]1(C)c2cccc3cccc(c23)[Sb]1([O+])[O+]</smiles>

G

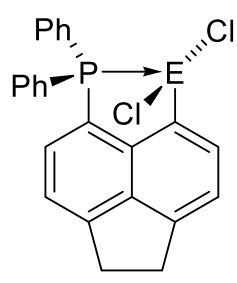

$\mathrm{J}: \mathrm{E}=\mathrm{P}, \mathrm{As}, \mathrm{Bi}$<smiles>CN(C)c1cccc2cccc([Se](=O)(O)(Cl)Cl)c12</smiles>

$\mathrm{H}$<smiles></smiles>

Figure 1: Structural formulae of species mentioned in the text.

Due to their lesser $\sigma$-donating capacity, arsines, stibines and bismuthines act as donors in Main Group complexes less commonly. On the other hand, the increased Lewis acidity of heavier Group 15 halides means that they readily become involved as acceptors, even with weak donors. An example of this is an early structural report of $\mathrm{Me}_{3} \mathrm{Sb} \rightarrow \mathrm{SbI}_{2} \mathrm{Me}^{[6]}$ Two molecules of similar geometry are present in the asymmetric unit, both with $\mathrm{Sb}-\mathrm{Sb}$ distances corresponding to that of a Sb-Sb single bond (2.859(1) and 2.868(1) $\AA$ ). The donor atom adopts a tetrahedral geometry and the acceptor adopts a tbp geometry with one of the equatorial positions occupied by a lone pair. Weak secondary Sb $\cdots$ I (intermolecular) interactions are present which extend the coordination of the acceptor Sb atom to 6 .

The tendency of the heavier Group 15 acceptors to extend their coordination beyond 4 (in the solid state) is almost ubiquitous as secondary interactions result in the formation of 
loosely bound oligomeric or polymeric structures consisting of strongly bound monomers or dimers. An example of this is $\left[\left(\mathrm{SbI}_{3}\right)\left(\mathrm{PMe}_{3}\right)\right]_{2}$, which in the solid state forms a weakly bound polymer consisting of dimeric units. $^{[7]}$ An exception is the dimeric adduct $\left[\left(\mathrm{SbMe}_{3}\right)\left(\mathrm{SbI}_{3}\right)(\mathrm{THF})\right]_{2}$, in which the THF coordination seems to block further association of the dimeric units. ${ }^{[8]}$ An early review by Norman gives an overview of the complexity and structural variety displayed by phosphine-pnictine adducts, and also provides data on related anionic species. ${ }^{[9]}$ A comprehensive study on a range of phosphine adducts with cationic, neutral and anionic antimony halide motifs $\left([\mathrm{SbCl}]^{2+},\left[\mathrm{SbCl}_{2}\right]^{+}, \mathrm{SbCl}_{3}\right.$ and $\left.\left[\mathrm{SbCl}_{4}\right]^{-}\right)$has been reported more recently. ${ }^{[10]}$

Employing a rigid organic backbone provides a degree of molecular geometry control with respect to the donor-acceptor interaction. Norman utilised peri-substitution and other related systems to study amine-stibine interactions. ${ }^{[11]}$ The single donor complex $\mathbf{E}$ displayed short $\mathrm{N} \rightarrow \mathrm{Sb}$ interaction. In the double donor species $\mathbf{F}$ only one amine group is strongly interacting with the $\mathrm{Sb}$ acceptor, whilst the other shows a weak nonbonding interaction as reflected by the respective Sb-N distances (2.219(4) and 2.903(4) $\AA$ ).

A small series of $\mathrm{Sb}^{\mathrm{III}}$ and $\mathrm{Sb}^{\mathrm{V}}$ donor-acceptor complexes with naphthalene and $o$ phenylene scaffolds was synthesised by Yamaguchi. ${ }^{[12]}$ Only a weakly bonding $\mathrm{N} \cdots \mathrm{Sb}$ interaction was found in $\mathbf{G}$, whilst the shorter $\mathrm{N}-\mathrm{Sb}$ distance in $\mathbf{H}$ indicated a dative bond was present. Interestingly the derivative with an extra methylene bridge I showed a slightly shorter N-Sb distance than $\mathbf{H}(2.590(6)$ vs. 2.658(4) $\AA$ ), indicating the rigidity of the peribackbone is hindering efficient $\mathrm{N}-\mathrm{Sb}$ interaction slightly. ${ }^{[12]}$

Very recently, Beckmann reported a comprehensive series of phosphine-pnictine species shown in Figure 1. ${ }^{[13]}$ All species show a strong attractive P-E interaction. Interestingly, the structure of the antimony species $\mathbf{K}$ differs fundamentally from all others by possessing a near-linear $\mathrm{P}-\mathrm{Sb}-\mathrm{Cl}$ motif. Extensive analysis by a variety of computational methods is given in the paper, however it seems there is no simple explanation as to why the structure of $\mathbf{K}$ is anomalous. Most likely the structure is driven by differences in local environment polarity in the individual crystal lattices; indeed calculations show that polarity effects can result in switch of the energy minima for the two forms shown in Figure 1. ${ }^{[13]}$

The $\beta$-diketiminate scaffold has also been used to support the phosphine-stibine and phosphine-arsine donor-acceptor complexes $\mathbf{L}$ by Burford (Figure 1). ${ }^{[14]}$

In this paper, a comprehensive series of phosphine-stibine and phosphine-stiborane species are reported. Peri-substitution supported motifs have been designed with view of observing a series of $\mathrm{P} \rightarrow \mathrm{Sb}$ dative interactions using a fixed donor motif and $\mathrm{Sb}$ acceptor 
with progressively increasing Lewis acidity. We wished to establish whether sudden structural changes consistent with a clear distinction between bonding and non-bonding (repulsive, frustrated) interaction will be observed, or whether smooth trend of $\mathrm{P}-\mathrm{Sb}$ distances will be produced in the series consistent with a "spectrum-like" character of the dative interaction. Indeed, differentiation of "primary" and "secondary" coordination in main group chemistry was mentioned by Levason in a recent review as one of the issues in contemporary Main Group chemistry. ${ }^{[3 b]}$ In this paper we provide insight into these interactions using combination of experimental (structural, spectroscopic) and computational approaches.

\section{Results \& Discussion}

\section{Synthesis}

A comprehensive series of phosphorus-antimony peri-substituted species was synthesised to study the onset of the donor-acceptor $\mathrm{P} \rightarrow \mathrm{Sb}$ bonding. While the donor $\left(-\mathrm{P} \operatorname{Pr}_{2}\right.$ group) is maintained throughout this series, the acceptor groups include all permutations of pentavalent groups $-\mathrm{SbCl}_{\mathrm{n}} \mathrm{Ph}_{4-\mathrm{n}}(\mathrm{n}=0-4$, compounds 5-9), as well as trivalent groups $\mathrm{SbCl}_{2},-\mathrm{Sb}(\mathrm{Ph}) \mathrm{Cl}, \mathrm{Sb}(\mathrm{Mes}) \mathrm{Cl}$ and $-\mathrm{SbPh}_{2}$ (compounds 2-4, Scheme 1).

5-Bromo-6-(diisopropylphosphino)acenaphthene (1) was used as a principal precursor in all syntheses described in this paper. ${ }^{[5 b]}$ The majority of the new compounds were prepared via low temperature halogen-lithium exchange reaction yielding 1', which was (without isolation) subjected to $\mathrm{C}-\mathrm{Sb}$ coupling reaction with variety of (aryl)antimony chloride species (Scheme 1). In case of $\mathbf{9}, \mathrm{Ph}_{4} \mathrm{SbBr}$ was used in the coupling reaction. The compounds were isolated as white to yellow powders with yields ranging from moderate to excellent (70$91 \%)$. 


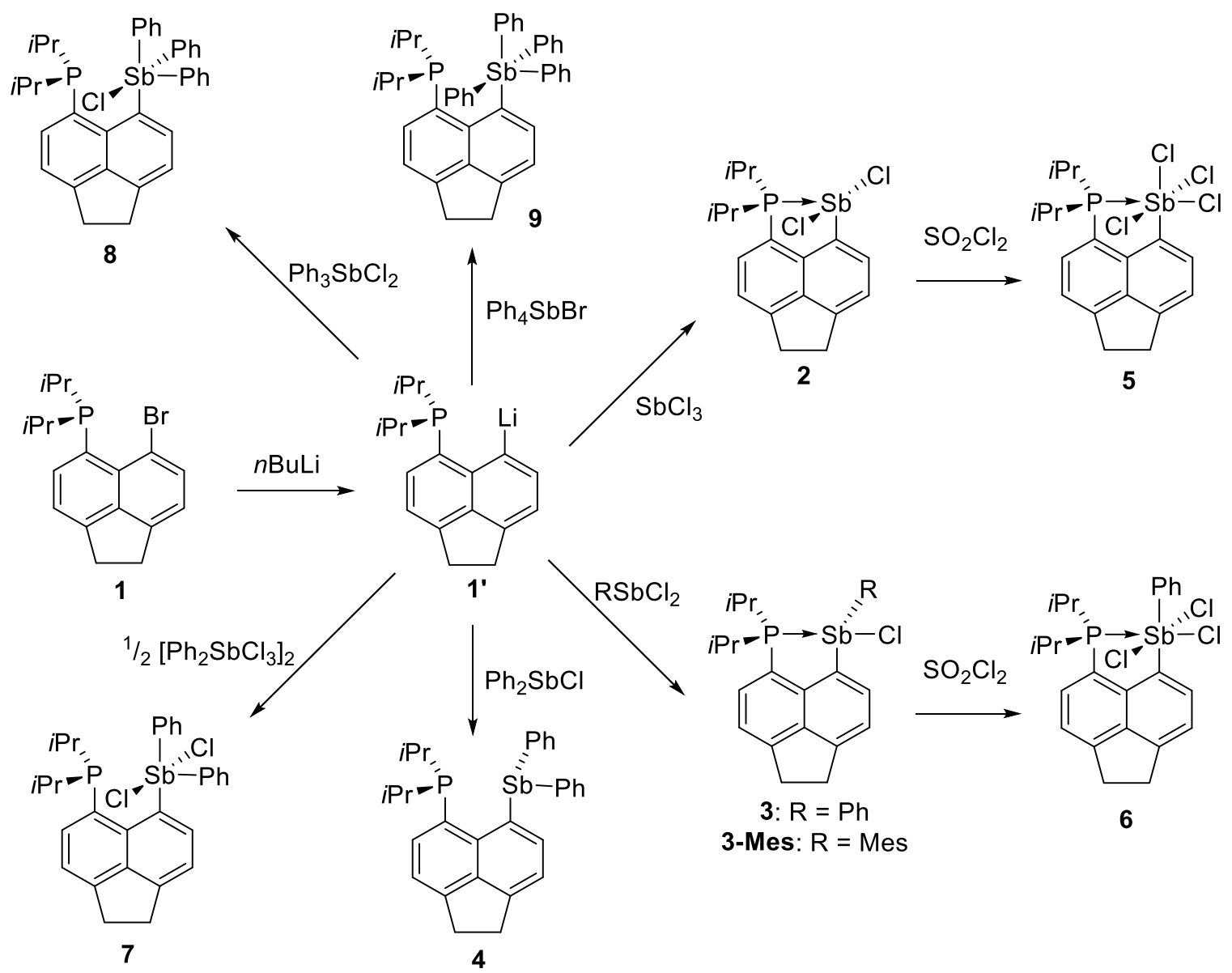

Scheme 1: Preparation of phosphorus-antimony peri-substituted acenaphthenes 2-9.

Compounds 5 and $\mathbf{6}$ were prepared by chlorination of the corresponding $\mathrm{Sb}^{\mathrm{III}}$ species 2 and 3 with sulfuryl chloride (Scheme 1); both these reactions afforded near quantitative yields. Our attempts to prepare these highly chlorinated $\mathrm{Sb}^{\mathrm{V}}$ species $(\mathbf{5}$ and $\mathbf{6})$ by reacting the lithiated acenaphthene precursor 1' with $\mathrm{SbCl}_{5}$ and $\mathrm{PhSbCl}_{4}$, respectively, resulted in complex mixtures as indicated by ${ }^{31} \mathrm{P}$ NMR spectra. In the case of the reaction with $\mathrm{PhSbCl}_{4}$, somehow unexpectedly, a product of a scrambling reaction (compound 7) was observed as a minor component in the mixture after the reaction. The observed lack of chemoselectivity of these couplings is likely stemming from the extremely electrophilic nature of the highly chlorinated $\mathrm{Sb}^{\mathrm{V}}$ precursor species.

Compound 5 was isolated as a thermally unstable yellow powder, which can however be stored at $-30{ }^{\circ} \mathrm{C}$. In the solid state visible signs of decomposition (colour change to brown) are observed within 2-3 days at room temperature when stored under argon. The decomposition is instant in chlorinated solvents, while in benzene or toluene solutions the decomposition was slow enough that it was possible to acquire complete set of solution NMR spectra. 
All new species with the exception of $\mathbf{5}$ are hydrolytically stable, including those containing $\mathrm{Sb}-\mathrm{Cl}$ linkages. This allowed efficient removal of ionic impurities after the $\mathrm{Sb}-\mathrm{C}$ coupling reactions through washing with degassed water. In the series of $E^{I I I}$ congeners $\mathbf{A}^{[5 b]}$ $(\mathrm{E}=\mathrm{P}), \mathbf{B}^{[15]}(\mathrm{E}=\mathrm{As})$ and $\mathbf{2}(\mathrm{E}=\mathrm{Sb}$, reported herein $)$ an expected trend is observed of increasing hydrolytic stability with the increase of metallic character of pnictogen atom (on descending Group 15), with phosphorus species A hydrolysing instantly, arsenic species B being moderately sensitive and antimony species $\mathbf{2}$ being fully resistant to hydrolysis.

Novel compounds 2-9 were fully characterised by multinuclear NMR $\left({ }^{1} \mathrm{H},{ }^{13} \mathrm{C}\right.$ and ${ }^{31} \mathrm{P}$ ), single crystal X-ray diffraction, MS, IR and Raman spectroscopy. The homogeneity, where possible, was confirmed using microanalysis.

\section{Structural Investigations}

\section{Antimony(III) species}

The series of antimony(III) species includes 2, 3, 3-Mes and 4. Despite the P-Sb distances varying widely in these species, the acenaphthene backbones remain essentially planar, while the out-of-plane displacements are small to moderate at $0.111-0.240 \AA$ for the $\mathrm{P}$ atom and 0.011-0.207 $\AA$ for the Sb atom (Figure 6). Splay angles increase uniformly in this series (from $-1(1)$ in 2 to $+15.7(4)$ in 4 (see Figure S5 in Supporting information for splay angle definition). The phosphorus atoms in the phosphine groups attain distorted tetrahedral geometry; in all cases the conformation with the lone pair pointing (at least approximately) towards the antimony atom is observed in the solid state structures as shown in Figure 6. 

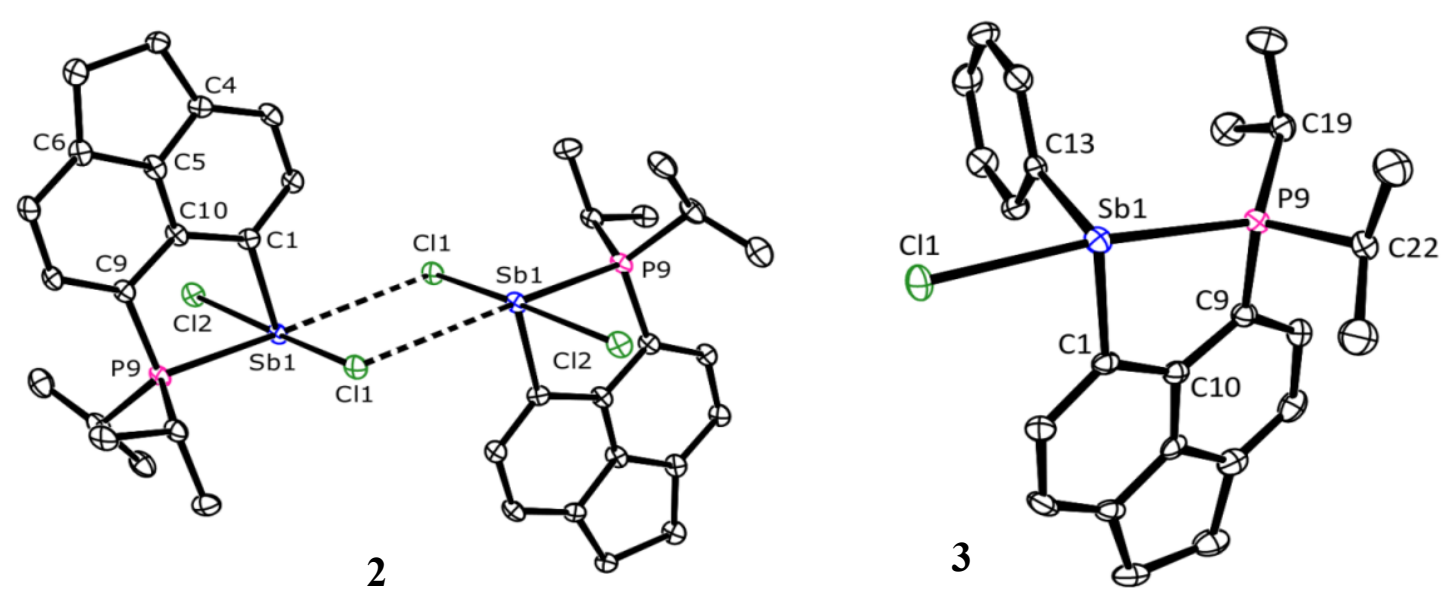

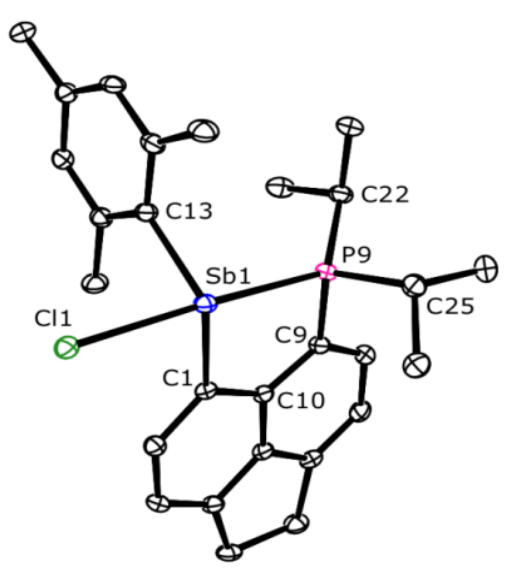

3-Mes

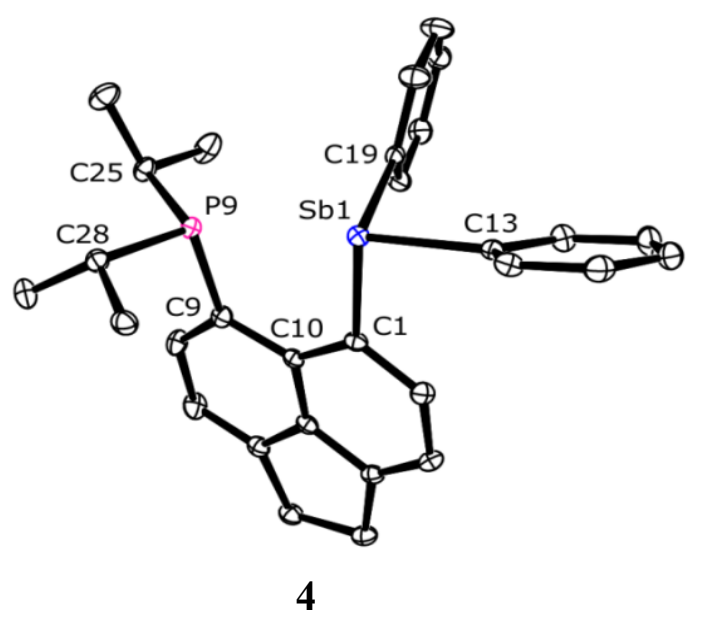

Figure 2: X-ray structures of 2 (showing the loosely bound dimeric assembly), 3, 3-Mes and 4. Hydrogen atoms and a molecule of solvating dichloromethane (from 2) are omitted for clarity.

The structure of $\mathbf{2}$ in the crystal is shown in Figure 2 and Table 1. A loosely bound centrosymmetric dimeric assembly is formed in the solid state through two $\mathrm{Sb} \cdots \mathrm{Cl}$ interactions (3.4233(17) $\AA$ ); both contacts are significantly shorter than the sum of the van der Waals radii $(4.15 \AA) .{ }^{[16]}$ The $\mathrm{Sb}$ atom in 2 adopts a rather distorted pseudo-trigonal bipyramidal geometry with chlorine atoms occupying the axial positions (Cl1-Sb1-Cl2 angle of $171.35(5)^{\circ}$ ) and atoms $\mathrm{P} 9, \mathrm{C} 1$ and the lone pair occupying the equatorial positions. The $\mathrm{P}-$ Sb distance in 2 is $2.5923(17) \AA$, which is within the normal range for $\lambda^{3} \mathrm{P}-\lambda^{3} \mathrm{Sb}$ bonds $(2.49-2.59 \AA){ }^{[17]}$ Along with the splay angle of $-1(1)^{\circ}$ this is consistent with an attractive interaction (i.e. a standard bond) between the phosphorus and antimony atom. Taking into account the $\mathrm{Sb} \cdots \mathrm{Cl}$ contacts within the dimer, the antimony atom geometry can be seen as distorted pseudo-octahedral with the chlorine atoms occupying the meridional positions and a close to linear arrangement of $\mathrm{P} 9-\mathrm{Sb} 1 \cdots \mathrm{Cl1}$ motif $\left(170.34(5)^{\circ}\right)$. Natural Bond Orbital 
(NBO) analysis indicates large s character of the lone pair on the antimony atom (87\% s-, and $13 \%$ p-character, Figure 3), which makes it difficult to assign the antimony geometry as tbp or octahedral based on the lone pair location.

Interestingly, the two $\mathrm{Sb}-\mathrm{Cl}$ bond lengths in $\mathbf{2}$ are statistically indifferent, although $\mathrm{Cl1}$ atom is involved in sub-van der Waals intramolecular contacts, whilst $\mathrm{Cl} 2$ atom is not. The C1-Sb1-P9 angle $\left(80.6(2)^{\circ}\right)$ is rather acute due to the constraints of the acenaphthene backbone.

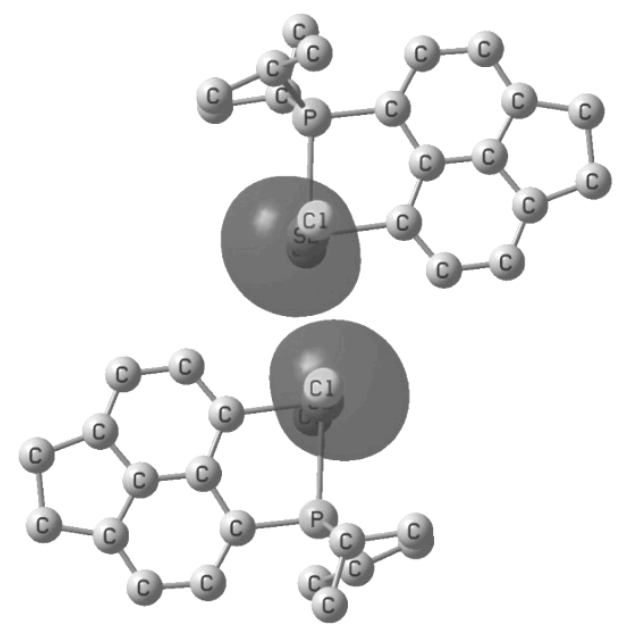

Figure 3: Plot of the lone pairs at the Sb atoms in the dimeric assembly of 2 (NBOs at the B3LYP/CPCM level, $87 \%$ and 13\% s and p character, respectively). Hydrogen atoms are omitted for clarity. See Supporting Information for the colour version.

The structure of $\mathbf{3}$ in the crystal is shown in Figure 2 and Table 1. The P-Sb distance of 2.7104(8) $\AA$ in 3 indicates an attractive interaction across the peri gap, although noticeably weaker than that found in 2 and slightly outside the normal range for $\lambda^{3} \mathrm{P}-\lambda^{3} \mathrm{Sb}$ bonds $(2.49$ $2.59 \AA) .{ }^{[17 a]}$ The splay angle in $\mathbf{3}$ is accordingly slightly larger $\left(2.8(6)^{\circ}\right) v s$. that in $\mathbf{2}$. The geometry around antimony in $\mathbf{3}$ is distorted pseudo-trigonal bipyramidal with the chlorine and phosphorus atoms occupying the axial positions (with C11-Sb1-P9 angle of $168.20(3)^{\circ}$ ) and atoms C1, C13 and the lone pair occupying the equatorial positions. Most remarkably, the geometric orientation of the substituents with respect to the acenaphthene ring differs in 2 and $\mathbf{3}$, with the tbp axis in $\mathbf{3}$ being parallel with the acenaphthene plane rather than perpendicular to it as in $\mathbf{2}$. The proximal location of one of the isopropyl groups to the phenyl rings is such that a weak intramolecular $\mathrm{CH}^{\cdots} \pi$ interaction can be observed, with H20B $\cdots \mathrm{Cg}(13-18)$ distance of $2.720 \AA$ (see Figure 15). 
The structure of 3-Mes in the crystal is shown in Figure 2 and Table 1. The overall structural characteristics of 3-Mes are very similar to those of 3. The P-Sb bond length of 2.7244(9) $\AA$ is only marginally longer than that in $\mathbf{3}$, and the splay angle of $3.1(5)^{\circ}$ is correspondingly slightly more obtuse. The C11-Sb1-P9 angle is $168.07(2)^{\circ}$, the Sb1-C13 bond lengths differ slightly in $3(2.152(3) \AA)$ and in 3-Mes $(2.176(2) \AA)$. The largest structural difference between $\mathbf{3}$ and $\mathbf{3 - M e s}$ is in the $\mathrm{C} 1-\mathrm{Sb} 1-\mathrm{C} 13$ angle $\left(95.1(1)^{\circ}\right.$ vs. $\left.108.58(8)^{\circ}\right)$. Hence the inclusion of the methyl groups results not only in a slight increase of electron releasing character of the mesityl group (mirrored in minor P9-Sb1 and Sb1-C13 elongation), but also in an increased steric clash between the aryl group (in particular the ortho-methyl groups) and both the acenaphthene skeleton and the isopropyl groups.

The structure of $\mathbf{4}$ in the crystal is shown in Figure 2 and Table 1. The P...Sb distance of 3.191(1) $\AA$ combined with the splay angle of $15.7(4)^{\circ}$ indicates there is no conventional bonding interaction between antimony and phosphorus. The antimony atom adopts a distorted trigonal pyramidal geometry with rather acute angles $\left(\Sigma=285^{\circ}\right)$. Close to linear arrangement of $\mathrm{P} 9 \cdots \mathrm{Sb} 1-\mathrm{C} 13$ motif $\left(168.14(6)^{\circ}\right)$ and the phosphorus lone pair pointing towards the antimony however indicates an onset of $3 \mathrm{c}-4 \mathrm{e}$ interaction $\left(\mathrm{n}(\mathrm{P} 9) \rightarrow \sigma^{*}(\mathrm{Sb} 1-\mathrm{C} 13)\right.$; this is further corroborated by a slightly elongated Sb1-C13 bond (2.183(2) A) with respect to the Sb1-C19 bond (2.152(2) Å).

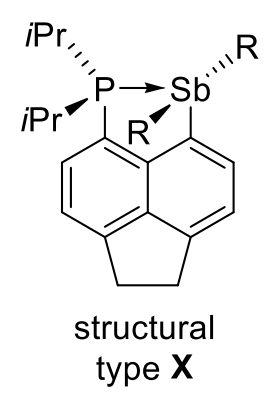<smiles>[R]C([PH])[Sb]1([R])c2ccc3c4c(ccc(c24)P1[R])CC3</smiles>

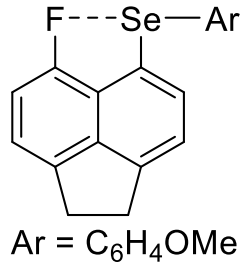

M<smiles>CC(C)P(c1ccccc1)c1ccc2c3c(ccc(P(c4ccccc4)P(c4ccccc4)C(C)C)c13)CC2</smiles>

$\mathbf{N}$<smiles>[R][PH]1c2ccc3c4c(ccc(c24)[PH]1(F)(F)=P)CC3[PH2+]</smiles>

O

Figure 4: The two structural types identified in the reported $\mathrm{Sb}^{\mathrm{III}}$ series ( $\mathbf{X}$ and $\mathbf{Y}$ ) and structural formulas of compounds mentioned in the discussion. 
Two distinct structural types ( $\mathbf{X}$ and $\mathbf{Y}$, Figure 4) have been identified in the series of the $\mathrm{Sb}^{\mathrm{III}}$ species $\mathbf{2}-\mathbf{4}$. Compound $\mathbf{2}$ attains structure $\mathbf{X}$ in the crystal, featuring linear $\mathrm{Cl}-\mathrm{Sb}-\mathrm{Cl}$ arrangement and a standard $\mathrm{P}-\mathrm{Sb}$ covalent bond. The other structural type (Y) has approximately linear $\mathrm{P}-\mathrm{Sb}-\mathrm{R}$ arrangement $(\mathrm{R}=\mathrm{Cl}, \mathrm{Ph}, \mathrm{Mes})$ and features either a weakened $\mathrm{P}-\mathrm{Sb}$ bond (as in 3 and 3-Mes), or an essentially non-bonding $\mathrm{P} \cdots \mathrm{Sb}$ interaction as in $\mathbf{4}$. In a recent paper, ${ }^{[13]}$ a related peri-substituted species $\mathbf{K}$ (Figure 1) was reported, which features a less Lewis basic phosphine group. In the crystal, $\mathbf{K}$ adopts structure $\mathbf{Y}$ with a $\mathrm{P} \cdots \mathrm{Sb}$ distance of 2.808(1) $\AA$, which is only slightly elongated with respect to that in 3 (2.7104(8) and 3-Mes (2.7244(9) A). Extensive computations indicated that "electric field" (such as from polar crystal lattice or polar solvent) promotes adoption of structure type $\mathbf{X}$ by $\mathbf{K}$, but in the gas phase structure $\mathbf{Y}$ is the ground state. ${ }^{[13]}$ Our calculations (including polarizable continuum model for $\mathrm{CHCl}_{3}$ ) indicate that enthalpy difference for $\mathbf{3} / \mathbf{3}^{\prime}$ ' is $51.3 \mathrm{~kJ} \mathrm{~mol}^{-1}$ (see Figure 8), i.e. the structural type $\mathbf{Y}$ is strongly preferred for $\mathbf{3}$ even in the polar environment. On the other hand, when modelling in the same environment the structural preference is reversed for 2, the isomer 2' (type $\mathbf{Y}$ ) being $15.3 \mathrm{~kJ} \mathrm{~mol}^{-1}$ higher in enthalpy than isomer $\mathbf{2}$ (type $\mathbf{X}$ ). This leads us to conclude that structure $\mathbf{X}$ is stable when a very strong donor-acceptor interaction is in place, such as in $\mathbf{2}$, which combines very basic donor and rather acidic acceptor. Interestingly, the structure $\mathbf{X}$ appears to be limited to phosphine-donor systems as the dimethylamino derivative $\mathbf{E}$ adopts structure $\mathbf{Y}$ in the crystal despite strong $\mathrm{N} \rightarrow$ Sb interaction (2.460(4) $\AA) .^{[11]}$

The $\mathrm{P} \rightarrow \mathrm{Sb}$ derivatives with either less Lewis basic donor $(\mathbf{K})$ or less Lewis acidic acceptor (3, 3-Mes and 4) adopt structure $\mathbf{Y}$, which is driven by a formation of the $\mathrm{n}(\mathrm{P}) \rightarrow \sigma^{*}(\mathrm{Sb}-\mathrm{R}) \quad 3 \mathrm{c}-4 \mathrm{e}$ interaction. Indeed, 3c-4e bonding has been shown to drive conformational preferences in a wide range of peri-substituted species, stretching from 1fluoro-8-anisylchalcogenyl naphthalene $\mathbf{M}^{[4 a, 18]}$ to heteroleptic bis(phosphino)acenaphthene $\mathbf{N}$ (Figure 4). ${ }^{[19]}$

The observations above prompt a query as to how the bonding can be classified in the compounds of the $\mathrm{Sb}^{\mathrm{III}}$ series. Using definitions of donor-acceptor (DA) bonding delineated in Haaland's seminal review, ${ }^{[20]} \mathbf{2}$ would fail to be classified as phosphine-stibine DA complex, as its $\mathrm{P}-\mathrm{Sb}$ bond length lies within the range of normal covalent bonds. ${ }^{[21]}$ This corresponds well with our computed Wiberg Bond Indices of 0.73 (gas phase, see computational part for details). On the other hand, lessening of the accepting ability of $\mathrm{Sb}$ moiety by replacing one or two strongly electronegative chlorine ligands with more electron releasing aryl groups leads to small (in $\mathbf{3}$ and 3-Mes) or significant (in 4) elongation of the P- 
Sb distance, concomitant with a major change in bonding geometry. Hence the latter species comply with Haaland's definition of DA bonding more than the former.

According to VSEPR model, normal bond pairs (NBP) are more spatially demanding than the accepted bond pairs (ABP). ${ }^{[20]}$ When bonded via a dative bond, it is expected that the $\mathrm{P}$ atom (bearing an $\mathrm{ABP}$ ) should occupy an axial position in the tbp environment of $\mathrm{Sb}$ atoms in 2-4, similar to for example $\mathrm{NMe}_{3}$ donor occupying an axial position in the tbp adduct of $\mathrm{Me}_{3} \mathrm{~N} \rightarrow \mathrm{SiF}_{4} \cdot{ }^{[20]}$ Indeed, the $\mathrm{P}$ donor atom is occupying the axial position in $\mathbf{3}, \mathbf{3}$-Mes and 4 (structure $\mathbf{Y}$ ). In contrast, in $\mathbf{2}$ (structure $\mathbf{X}$ ), the two $\mathrm{Cl}$ atoms occupy axial positions in the antimony atom tbp environment, with the $\mathrm{P}$ donor being in equatorial position. By this, the $\mathrm{P}-$ $\mathrm{Sb}$ bond in $\mathbf{2}$ again resembles more the "normal" bond rather than the dative one.

It is interesting to note that while $\mathbf{3}$ and $\mathbf{3}$-Mes are molecular entities with only slightly elongated $\mathrm{Sb}-\mathrm{Cl}$ bonds (2.6798(8) $\AA$ and 2.6682(9) $\AA$ ) compared to the axial Sb-Cl bonds in $\mathrm{Ph}_{3} \mathrm{SbCl}_{2}\left(2.4820(5)\right.$ and 2.4925(5) $\AA$ ), ${ }^{[22]}$ the related phosphorus species $\mathbf{O}$ (Figure 4) display $\mathrm{P}-\mathrm{P}$ bonded ionic separated structure with $\mathrm{Cl}^{-}$as counterion. ${ }^{[23]}$

\section{Antimony(V) species}

Since an interesting structural variety and differing strengths of DA bonding were observed in the $\mathrm{Sb}^{\mathrm{III}}$ series (see above), we expanded our study towards the related $\mathrm{Sb}^{\mathrm{V}}$ compounds 5 9. We expected that the lesser structural flexibility in the $\mathrm{Sb}^{\mathrm{V}}$ series (only octahedral coordination of $\mathrm{Sb}$ was anticipated) will result in a smoother onset of the DA bonding. In addition, increased coordinative saturation of $\mathrm{Sb}$ centres was expected to eliminate formation of secondary (intermolecular) contacts resulting in less complex bonding.

Rather strikingly, whilst the chemistry of phosphine complexes of $\mathrm{Sb}^{\mathrm{III}}$ halides has been well explored and a number of structural reports appeared in the literature ${ }^{[7,10,24]}$ no structural reports on phosphine or arsine complexes of $\mathrm{Sb}^{\mathrm{V}}$ halides (or, more generally, stiboranes $\mathrm{R}_{5} \mathrm{Sb}$ ) have been found in the literature to date. Compound $\mathbf{5}$ and other species in this series thus represent the first examples of such electroneutral complexes with the general formula $\mathrm{R}_{3}{ }_{3} \mathrm{P} \rightarrow \mathrm{SbR}_{5}$. This is rather surprising, especially considering that stiboranes and in particular $\mathrm{Sb}^{\mathrm{V}}$ halides are expected to be more Lewis acidic than the respective stibines and $\mathrm{Sb}^{\mathrm{III}}$ halides and hence DA complexes in which stiboranes act as acceptors should be stable. Indeed, calculated binding enthalpies (B3LYP/CPCM level) for prototypical $\mathrm{PMe}_{3}$ adducts of $\mathrm{SbCl}_{3}$ and $\mathrm{SbCl}_{5}$ are $-54.9 \mathrm{~kJ} \mathrm{~mol}^{-1}\left(-72.2 \mathrm{~kJ} \mathrm{~mol}^{-1}\right)$ and $-147.3 \mathrm{~kJ} \mathrm{~mol}^{-1}\left(-175.5 \mathrm{~kJ} \mathrm{~mol}^{-1}\right)$, respectively (values in parentheses include BSSE and dispersion corrections at the B3LYP- 
D3 level). The early literature describes reaction of $\mathrm{PMe}_{3}$ with $\mathrm{SbCl}_{5}$ as rapid ${ }^{[25]}$ however no follow up of this reactivity is available. We believe this unexpected absence may be due to the redox reactions plaguing this and similar systems, with $\mathrm{Sb}^{\mathrm{V}}$ oxidising the phosphine. ${ }^{[26]}$

Despite differing P-Sb distances in the series of 5-9 (range of 2.6199(8) - 3.1248(16) $\AA)$ the acenaphthene backbones remain essentially planar, while the out-of-plane displacements are small to moderate at $0.038-0.289 \AA$ for the $\mathrm{P}$ atom and $0.012-0.137$ for the $\mathrm{Sb}$ atom (Figure 6). The phosphorus atoms in the phosphine groups attain distorted tetrahedral geometry; in all cases the conformation with the lone pair pointing towards the antimony atom is observed (Figure 6) and the angle C9-P9-Sb1 is rather acute (91.6(2) $\left.95.7(3)^{\circ}\right)$ due to constraints of the backbone.

The perchlorinated compound $\mathbf{5}$ was isolated as a yellow powder which is thermally unstable at room temperature. Crystals suitable for $\mathrm{X}$-ray diffraction were grown from toluene at $-35{ }^{\circ} \mathrm{C}$; these contained one molecule of solvated toluene per molecule of 5 . The structure of 5 in the crystal is shown in Figure 5 and Table 1. The P-Sb distance of 2.6199(8) $\AA$ is the shortest amongst the $\mathrm{Sb}^{\mathrm{V}}$ compounds 5-9, and is only slightly longer than the shortest known $\lambda^{3} \mathrm{P} \rightarrow \lambda^{5} \mathrm{Sb}$ bond, which was observed in a tetrameric bis(phosphine) complex $\left[\left(\mathrm{SbBr}_{3}\right)_{4}(\mathrm{dmpe})_{4}\right]$ (P-Sb bond lengths in this complex range from 2.498(6) to 2.656(4) $\AA$, bridging halide atoms provide the extra coordination to $\mathrm{Sb}$ centres). ${ }^{[7]}$ Comparison with normal (i.e. non-dative) $\lambda^{3} \mathrm{P}-\lambda^{5} \mathrm{Sb}$ bond length is not possible as no structural reports on species containing a non-dative bond have appeared in the literature to date. The splay angle of $1.1(7)^{\circ}$ in $\mathbf{5}$ is the smallest observed amongst the $\mathrm{Sb}^{\mathrm{V}}$ compounds $5-9$. The antimony atom adopts a distorted octahedral geometry with cis-angles ranging from $83.51(8)^{\circ}$ (P9-Sb1-C1) to $95.63(8)^{\circ}(\mathrm{Cl} 1-\mathrm{Sb} 1-\mathrm{C} 1)$. The $\mathrm{Sb}-\mathrm{Cl}$ distances in $\mathbf{5}$ are the shortest observed in this series ranging from 2.3732(10) $\AA$ [Sb1-Cl1] to 2.4159(9) [Sb1-Cl2] (cf. 2.4820(5) and 2.4925(5) $\AA$ in $\left.\mathrm{Ph}_{3} \mathrm{SbCl}_{2}\right)$. ${ }^{[22]}$ 


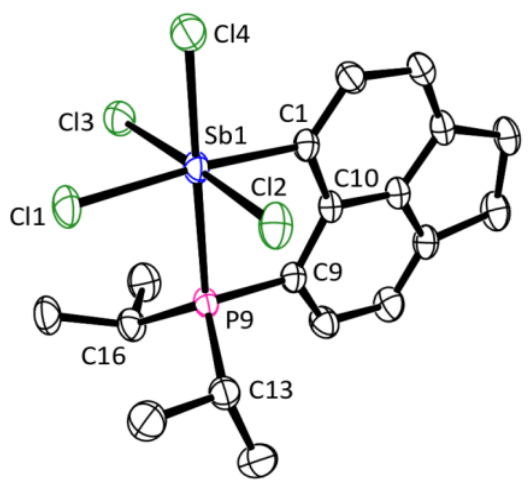

5

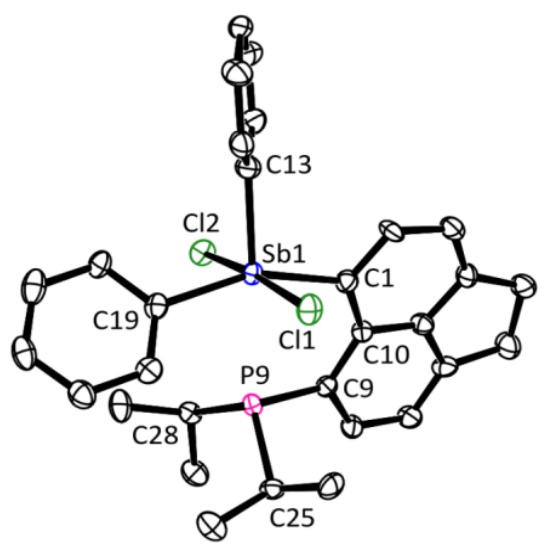

7

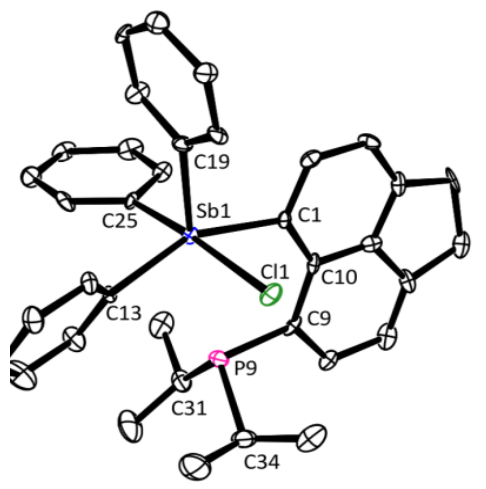

8

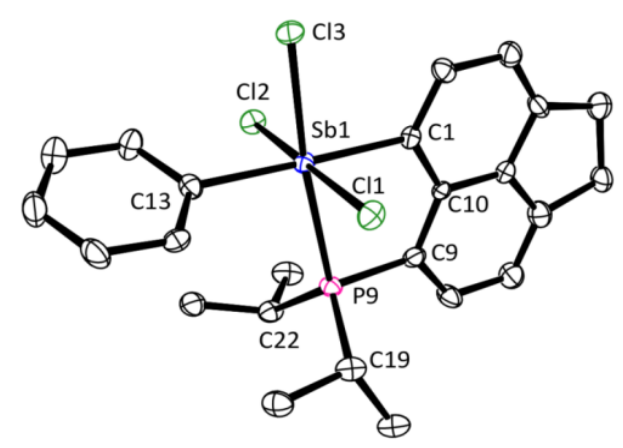

6

Figure 5: X-ray structures of 5-9. Hydrogen atoms and solvated molecules of toluene in $\mathbf{5}$ and acetonitrile in $\mathbf{8}$ are omitted for clarity.

The structure of 6 in the crystal is shown in Figure 5 and Table 1. The antimony atom adopts a distorted octahedral geometry with phenyl group placed trans to the backbone's $\mathrm{C} 1$ atom. The $\mathrm{P}-\mathrm{Sb}$ distance of 2.659(2) $\AA$ in $\mathbf{6}$ is only very moderately elongated $v s$. that in $\mathbf{5}$ (2.6199(8) A , indicating a bonding interaction. This is further supported by only a marginal increase in splay angle to $3(1)^{\circ}$. The cis angles around the $\mathrm{Sb}$ atom range from $86.7(3)^{\circ}$ $(\mathrm{C} 13-\mathrm{Sb} 1-\mathrm{Cl})$ to $99.9(3)^{\circ}(\mathrm{C} 13-\mathrm{Sb} 1-\mathrm{P} 9)$. The $\mathrm{Sb}-\mathrm{Cl}$ distances in 6 are slightly, but noticeably elongated $v s$. those in 5 to $2.449(2)-2.469(2) \AA$, in agreement with increased electron density at the antimony atom in $\mathbf{6} v s .5$.

The structure of 7 in the crystal is shown in Figure 5 and Table 1. The octahedral geometry around antimony is noticeably distorted in 7 , with cis angles of $88.10(18)^{\circ}$ [C1$\mathrm{Sb} 1-\mathrm{Cl1}]$ to $102.4(3)^{\circ} \quad[\mathrm{C} 1-\mathrm{Sb} 1-\mathrm{C} 13]$ and the trans angle $\mathrm{C} 1-\mathrm{Sb} 1-\mathrm{C} 19$ 157.7(3) . Nevertheless, the fact that $\mathrm{Sb}$ adopts a near- octahedral geometry indicating the phosphorus atom is part of its coordination sphere. The most striking feature is a significant elongation of the $\mathrm{P} \cdots \mathrm{Sb}$ distance to $2.9925(8) \AA$, which is $11 \%$ longer than that in 6 and $12 \%$ longer than 
that in 5. Despite the elongation, the distance remains significantly sub-van der Waals at $73 \%$ of the $\Sigma_{\mathrm{VdW}}(\mathrm{P}, \mathrm{Sb})=4.15 \AA .{ }^{[16]}$ In addition, peri-atoms are significantly displaced from the acenaphthene mean plane (P9 0.289, Sb1 $-0.137 \AA$ ), and the splay angle is increased to $10(1)^{\circ}$, indicating noteworthy out-of-plane as well as in-plane distortions in the peri-region. These structural features indicate a rather ambiguous bonding situation in 7, with both repulsive and attractive terms, perhaps best described as weakly bonding $\mathrm{P} \cdots \mathrm{Sb}$ interaction. Our computations give WBI (Wiberg Bond Indices) of 0.29 in 7 (in the crystal structure), which is significantly lower than those in $5(0.57)$ and $6(0.53)$, yet indicate the presence of a significant covalent bonding component. The two chlorine atoms in $\mathbf{7}$ are placed trans to each other, with the $\mathrm{Cl}-\mathrm{Sb}-\mathrm{Cl}$ motif perpendicular to the acenaphthene plane, hence ruling out potential 3c-4e bonding involving donation of lone pair density on $\mathrm{P}$ atom into low lying $\sigma^{*}(\mathrm{Sb}-\mathrm{Cl})$ orbital as seen in $\mathbf{3}$ and 3-Mes. Instead, the $\mathrm{n}(\mathrm{P} 9) \rightarrow \sigma^{*}(\mathrm{Sb} 1-\mathrm{C} 13)$ interaction is present with the P9 $\cdots$ Sb1-C13 angle of 169.07(17).

Crystals of $\mathbf{8}$ suitable for $\mathrm{X}$-ray diffraction were grown from acetonitrile at $0{ }^{\circ} \mathrm{C}$. The structure of $\mathbf{8}$ in the crystal is shown in Figure 5 and Table 1, the molecule crystallises with a solvated molecule of MeCN. The geometry around $\mathrm{Sb}$ atom in $\mathbf{8}$ is rather similar to that in 7 , with the $\mathrm{P} \cdots \mathrm{Sb}$ distance of $3.088(3) \AA$ ( $3 \%$ elongation on 7$)$ and splay angle of $13.9(7)^{\circ}\left(4^{\circ}\right.$ more obtuse than 7). Interestingly, a much smaller out-of-plane distortion in the peri-region is observed with the $\mathrm{P}$ and $\mathrm{Sb}$ atoms being displaced from the mean acenaphthene plane only by 0.041 and $-0.012 \AA$. As in 7, the near-linear arrangement of P9 $\cdots$ Sb1-C19 motif $\left(171.6(2)^{\circ}\right)$ indicates a $\mathrm{n}(\mathrm{P} 9) \rightarrow \sigma^{*}(\mathrm{Sb} 1-\mathrm{C} 19) 3 \mathrm{c}-4 \mathrm{e}$ bonding interaction, resulting in a $\mathrm{P}-\mathrm{Sb}$ WBI of 0.25 .

The structure of 9 in the crystal is shown in Figure 5 and Table 1. The replacement of the last $\mathrm{Cl}$ atom on $\mathrm{Sb}$ atom with phenyl group leads to small elongation of the $\mathrm{P} \cdots \mathrm{Sb}$ distance to $3.1247(16) \AA$, whilst other metric parameters (including splay angle, $\mathrm{P}$ and $\mathrm{Sb}$ displacements) closely resemble those of $\mathbf{8}$. An overview of the crystal structures 2-9 aligned along the acenaphthene plane to show the geometry of the substituents around $\mathrm{Sb}$ and $\mathrm{P}$ atoms and relevant distortions of the backbone is provided in Figure 6. 


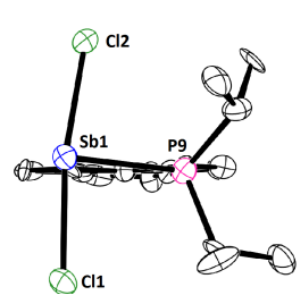

2

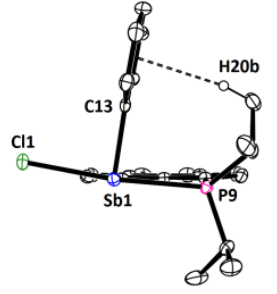

3

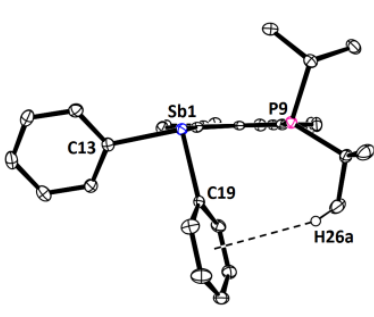

4

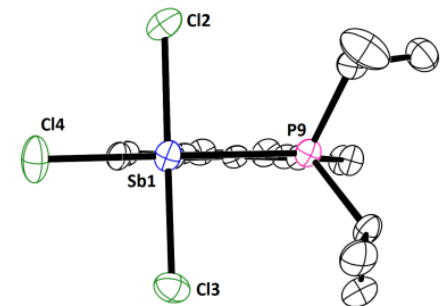

5 (axial Cl omitted)

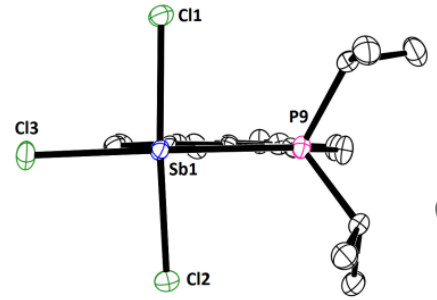

6 (axial Ph omitted)

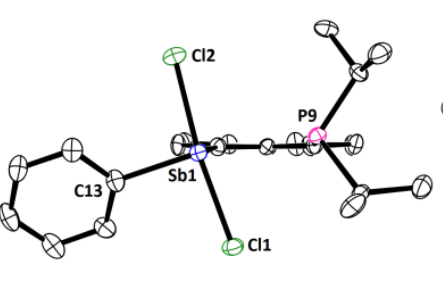

7 (axial Ph omitted)

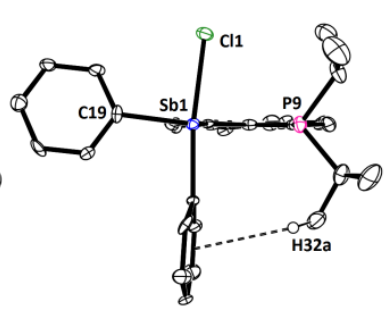

8 (axial Ph omitted)

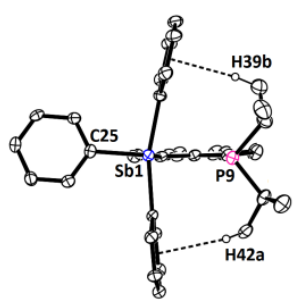

9 (axial Ph omitted)

Figure 6: Molecular structures of 2-9 in the crystal. Molecules are aligned along the acenaphthene plane to show the geometry of the substituents around $\mathrm{Sb}$ and $\mathrm{P}$ atoms. In each of the compounds 5-9, which have octahedral Sb environment, one of the substituents bound to $\mathrm{Sb}$ atom (pointing towards the viewer) has been omitted for clarity.

Table 1. Selected interatomic distances, displacements $[\AA]$, angles and torsion angles $\left[^{\circ}\right]$ for 2-9.

\begin{tabular}{|c|c|c|c|c|c|c|c|c|c|}
\hline Compound & 2 & 3 & 3-Mes & 4 & 5 & 6 & 7 & 8 & 9 \\
\hline \multicolumn{10}{|c|}{ peri-Region Bond Distances } \\
\hline $\mathrm{P} 9 \cdots \mathrm{Sb} 1$ & $2.5923(17)$ & $2.7104(8)$ & $2.7244(9)$ & $3.191(1)$ & $2.6199(8)$ & $2.659(2)$ & $2.9925(8)$ & $3.088(3)$ & $3.1247(16)$ \\
\hline$\% \Sigma \mathrm{r}_{\mathrm{vdW}}{ }^{a}$ & 62.5 & 65.3 & 65.6 & 76.9 & 63.1 & 64.1 & 72.1 & 74.4 & 75.3 \\
\hline P9-C9 & $1.802(6)$ & $1.807(3)$ & $1.805(2)$ & $1.847(2)$ & $1.796(3)$ & $1.815(9)$ & $1.829(6)$ & $1.810(7)$ & $1.843(3)$ \\
\hline $\mathrm{Sb} 1-\mathrm{C} 1$ & $2.153(6)$ & $2.182(2)$ & $2.181(2)$ & $2.183(2)$ & $2.132(3)$ & $2.149(8)$ & $2.132(8)$ & $2.180(7)$ & $2.218(4)$ \\
\hline $\mathrm{Sb} 1-\mathrm{Cl}$ & $\begin{array}{l}2.6160(17) \\
2.3124(17)\end{array}$ & $2.6798(8)$ & $2.6682(9)$ & - & $\begin{array}{l}2.373(1)- \\
2.4159(9)\end{array}$ & $\begin{array}{l}2.449(2)- \\
2.469(2)\end{array}$ & $\begin{array}{l}2.466(2) \\
2.486(2)\end{array}$ & $2.640(2)$ & - \\
\hline $\mathrm{Sb} 1-\mathrm{C}_{i p s o}$ & - & $2.152(3)$ & $2.176(2)$ & $\begin{array}{l}2.152(2) \\
2.183(2)\end{array}$ & - & $2.158(9)$ & $\begin{array}{l}2.131(7) \\
2.171(7)\end{array}$ & $\begin{array}{l}2.170(6)- \\
2.191(9)\end{array}$ & $\begin{array}{l}2.156(5)- \\
2.242(5)\end{array}$ \\
\hline \multicolumn{10}{|c|}{ peri-Region Bond Angles } \\
\hline C9-P9-Sb1 & $98.3(2)$ & $90.08(9)$ & $98.55(7)$ & $90.36(7)$ & $95.3(1)$ & $95.7(3)$ & $92.4(2)$ & $91.6(2)$ & $91.7(2)$ \\
\hline $\mathrm{C} 1-\mathrm{Sb} 1-\mathrm{P} 9$ & $80.6(2)$ & $78.12(7)$ & $78.03(6)$ & $73.88(5)$ & $83.51(8)$ & $81.5(3)$ & $75.4(2)$ & $74.5(2)$ & $73.9(1)$ \\
\hline $\begin{array}{l}\mathrm{P} 9-\mathrm{Sb} 1- \\
\mathrm{E}_{\text {trans }} \\
\text { Splay angle }^{c}\end{array}$ & $-1(1)$ & $168.20(3)$ & $168.07(2)$ & $97.48(8)$ & $179.08(3)$ & $173.30(8)$ & $169.1(2)$ & $\begin{array}{l}171.6(2) \\
13.9(7)\end{array}$ & $\begin{array}{l}172.1(1) \\
14(1)\end{array}$ \\
\hline \multicolumn{10}{|c|}{ Out-of-Plane Displacement } \\
\hline P9 & 0.271 & 0.240 & 0.190 & 0.111 & 0.185 & 0.038 & 0.289 & 0.041 & 0.102 \\
\hline $\mathrm{Sb} 1$ & -0.201 & -0.011 & 0.207 & -0.039 & 0.084 & -0.044 & -0.137 & -0.012 & -0.097 \\
\hline \multicolumn{10}{|c|}{ peri-Region Torsion Angle } \\
\hline $\begin{array}{l}\mathrm{P} 9-\mathrm{C} 9 \cdots \mathrm{C} 1- \\
\mathrm{Sb} 1\end{array}$ & $11.9(3)$ & $7.5(1)$ & $0.52(9)$ & $2.7(1)$ & $1.8(1)$ & $3.3(4)$ & $11.4(3)$ & $0.8(4)$ & $4.9(2)$ \\
\hline
\end{tabular}

${ }^{a}$ van der Waals radii used P: $1.95 \AA$, Sb: $2.20 \AA .{ }^{[16] b} \mathrm{E}=\mathrm{Cl}$ for 2, 3, 3-Mes, 5 and 6, $\mathrm{E}=\mathrm{C}$ for 4, 7-9. ${ }^{c}$ Splay angle: $\Sigma$ of the bay region angles $-360^{\circ}$ (see Figure S5 in Supporting Information). 


\section{NMR Spectroscopy}

Selected NMR and structural parameters of compounds 2-9 are shown in Table 2. All compounds exhibit sharp singlets in the ${ }^{31} \mathrm{P}\left\{{ }^{1} \mathrm{H}\right\}$ NMR spectra. It is expected that upon coordination (i.e. sequestration of its lone pair to a bonding interaction), the phosphorus atom becomes deshielded. In agreement with this, $\delta_{\mathrm{P}}$ in compounds $2-\mathbf{4}$ (the $\mathrm{Sb}^{\mathrm{III}}$ series) are increasingly shifted to low frequency as the Lewis acidity of the antimony centre decreases (most LA $2>3>3-M e s>4$ least LA).

However, only compounds 5-7 in the $\mathrm{Sb}^{\mathrm{V}}$ series follow the same trend. Whilst the Lewis acidity of antimony centres in 8 and 9 is clearly lower than those in 5-7 (as indicated by longer $\mathrm{P} \cdots \mathrm{Sb}$ distances and decreasing WBIs, Table 3 ), their $\delta_{\mathrm{P}}$ increase from -45.6 in 7 to -42.3 in 8 and -33.8 in 9 . Hence another effect appears to override the reduced removal of electron density from phosphorus due to decreasing dative bond strength. Aromatic ring currents from phenyl rings placed cis to $\mathrm{Sb}$ atom may (at least partially) contribute to the observed deshielding of the ${ }^{31} \mathrm{P}$ nucleus in $\mathbf{8}$ and $\mathbf{9}$ as the phosphorus atom is forced relatively close to the outside of these rings due to the congested nature of peri-substituted molecules.

Table 2: Selected NMR parameters of compounds 2-9.

\begin{tabular}{|c|c|c|c|}
\hline Compound & Sb Moiety & $\boldsymbol{\delta}_{\mathbf{P}}[\mathrm{ppm}]$ & ${ }^{\mathbf{5 t s}} \boldsymbol{J}_{\mathbf{C P}}[\mathrm{Hz}]^{a}$ \\
\hline \multicolumn{4}{|l|}{$\boldsymbol{S b}^{I I I}$ series } \\
\hline 2 & $\mathrm{SbCl}_{2}$ & 51.0 & - \\
\hline 3 & $\mathrm{Sb}(\mathrm{Ph}) \mathrm{Cl}$ & 1.5 & - \\
\hline 3-Mes & $\mathrm{Sb}$ (Mes)Cl & -3.6 & - \\
\hline 4 & $\mathrm{SbPh}_{2}$ & -21.9 & 40.3 \\
\hline \multicolumn{4}{|l|}{$\boldsymbol{S b}^{V}$ series } \\
\hline 5 & $\mathrm{SbCl}_{4}$ & -20.1 & - \\
\hline 6 & $\mathrm{Sb}(\mathrm{Ph}) \mathrm{Cl}_{3}$ & -28.4 & 52.3 \\
\hline 7 & $\mathrm{Sb}(\mathrm{Ph})_{2} \mathrm{Cl}_{2}$ & -45.6 & $86.4,77.8$ \\
\hline 8 & $\mathrm{Sb}(\mathrm{Ph})_{3} \mathrm{Cl}$ & -42.3 & 32.6 \\
\hline 9 & $\mathrm{SbPh}_{4}$ & -33.8 & $35.7,31.1$ \\
\hline
\end{tabular}

${ }^{a}$ Through space coupling from ${ }^{31} \mathrm{P}$ nucleus, observed on ipso-carbon atom( $(\mathrm{s})$ in the phenyl group(s).

Compounds 4 and 6-9 feature large ${ }^{13} \mathrm{C}-{ }^{31} \mathrm{P}$ through-space coupling $\left({ }^{\text {ts }} J_{\mathrm{CP}}\right)$ values $(31-87 \mathrm{~Hz})$ associated with the ipso carbon atoms of the phenyl substituents. These formally ${ }^{5} J_{\mathrm{CP}}$ couplings are listed in Table 2. Since the P..Sb distances in 2-9 are shorter than the sum of the van der Waals radii $\left(\Sigma \mathrm{r}_{\mathrm{vdW}}=4.15 \AA\right)$ there is the opportunity for an efficient overlap of 
the phosphorus lone pair and the $\sigma^{*}(\mathrm{Sb}-\mathrm{C})$ orbital (facilitated by the quasi linear $\mathrm{P} \cdots \mathrm{Sb}-\mathrm{C}$ ) arrangement, or the phosphorus lone pair and the $\sigma(\mathrm{Sb}-\mathrm{C})$ orbital as shown in Figure $7 .^{[27]}$
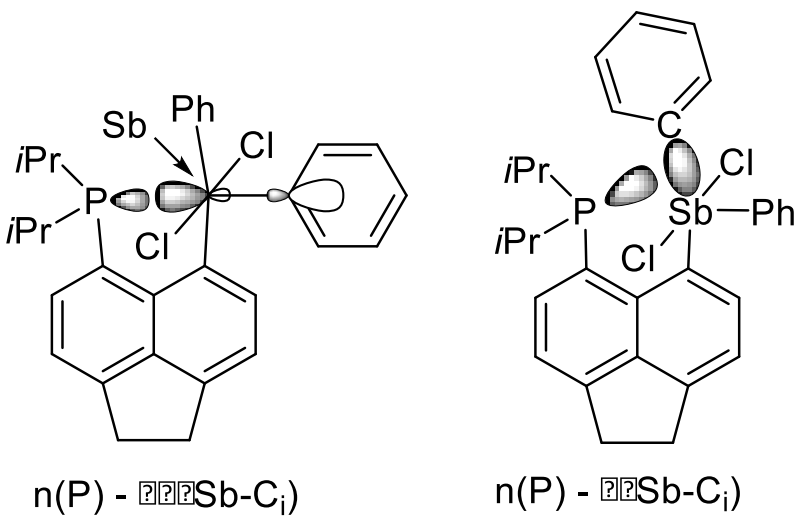

Figure 7: Diagram showing the origin of the through space coupling in 7 through overlap of the phosphorus lone pair with the $\sigma^{*}(\mathrm{Sb}-\mathrm{C})$ orbital (left) and the $\sigma(\mathrm{Sb}-\mathrm{C})$ orbital (right), observed magnitudes of the ${ }^{5 \mathrm{ts}} J_{\mathrm{CP}}$ constants in 7 are 86.4 and $77.8 \mathrm{~Hz}$.

Notably, magnitudes of the observed through-space couplings are larger than ${ }^{1} J_{\mathrm{CP}}$ throughbond couplings involving $\mathrm{P}^{\mathrm{III}}$ (e.g. $\mathrm{Me}_{3} \mathrm{P}{ }^{1} J_{\mathrm{CP}} 13.6 \mathrm{~Hz} ; t \mathrm{Bu}_{3} \mathrm{P} 33.9 \mathrm{~Hz}$ ) and of similar magnitude to ${ }^{1} J_{\mathrm{CP}}$ values in $\mathrm{P}^{\mathrm{V}}$ species (e.g. $\left.\mathrm{Ph}_{4} \mathrm{P}^{+} 88.4 \mathrm{~Hz} ; \mathrm{Ph}_{3} \mathrm{PO} 104.4 \mathrm{~Hz}\right){ }^{[28]}$

Compound $\mathbf{8}$ shows only one ${ }^{5 \text { ts }} J\left(\mathrm{C}_{\mathrm{ipso}}-\mathrm{P}\right)$ value $(32.6 \mathrm{~Hz})$ since all the phenyl rings are isochronous, presumably due to the their rapid interchange in solution akin to Berry pseudo rotation. This is different to 9 , (displaying ${ }^{5 \text { ts }} J\left(\mathrm{C}_{\mathrm{ipso}}-\mathrm{P}\right) 35.7,31.1$ and $0.0 \mathrm{~Hz}$ ) where three anisochronous phenyl environments are observed. Similar to 9, no scrambling of the phenyl substituents is observed in 7, presumably owing to the stronger $\mathrm{P} \cdots \mathrm{Sb}$ interaction.

The ${ }^{1} \mathrm{H}$ NMR spectrum of 9 shows a large difference $(c a .0 .93 \mathrm{ppm})$ in the $\delta_{\mathrm{H}}$ of the $\mathrm{CH}_{3}$ environments, indicating restricted rotation of the $i \mathrm{Pr}$ groups and spatial proximity to the ring current of the phenyl substituents orientated perpendicular to the P $\cdots$ Sb vector. Similar differences can be seen in the ${ }^{1} \mathrm{H}$ NMR spectra of 3, 3-Mes and 8 as these compounds also possess phenyl groups perpendicular to the $\mathrm{P} \cdots \mathrm{Sb}$ vector.

\section{Computational Analysis}

To complement the experimental findings, we performed Density Functional Theory calculations at the B3LYP/SDD/6-31(+) $\mathrm{G}^{*}$ level ${ }^{[29]}$ (compatible with our previous work). Optimised P-Sb distances and Wiberg Bond Indices (WBIs) ${ }^{[30][31]}$ are collected in Table 3. Consistent with results for related $\mathrm{P}-\mathrm{Sn}$ species, ${ }^{[32]}$ the $\mathrm{P}-\mathrm{Sb}$ distances in compounds with 
chlorine atoms trans to the phosphorus were considerably more affected by the environment compared to those with no chlorine atoms trans to the phosphorus (Table 3). While $\mathrm{P}-\mathrm{Sb}$ distances, when optimized in the gas phase, are significantly overestimated with respect to the values observed in the crystal (by up to $0.27 \AA$, see entry for 3 in Table 3 ), they shorten significantly when optimized in a continuum modelling a moderately polar solvent (chloroform in this case). Compounds without $\mathrm{Cl}$ atoms in trans positions are much less affected by the environment (see for instance entry for $\mathbf{2}$ in Table 3). This observation is readily explained by mesomeric resonance according to $\left[\mathrm{P}: \mathrm{Sb}-\mathrm{Cl} \leftrightarrow \mathrm{P}^{+}-\mathrm{Sb}: \mathrm{Cl}^{-}\right]$, where a polar environments favour the latter, ionic resonance structure.

Table 3: Phosphorus-antimony bond distances $(\AA)$ observed in the crystal and calculated at the B3LYP level. Wiberg Bond Indices obtained at the same level for the respective structures are displayed in square parentheses. For clarity, compounds for which X-ray diffraction data are available are in bold.

\begin{tabular}{|c|c|c|c|c|}
\hline Compound & $\begin{array}{l}d(\mathrm{P}-\mathrm{Sb})_{\mathrm{X}-\mathrm{ray}} \\
{[\mathrm{WBI}]^{a}}\end{array}$ & $\begin{array}{l}d(\mathrm{P}-\mathrm{Sb})_{\mathrm{calc}} \\
\text { gas [WBI] }\end{array}$ & $\begin{array}{l}d(\mathrm{P}-\mathrm{Sb})_{\text {calc }} \\
\mathrm{CPCM}[\mathrm{WBI}]^{b}\end{array}$ & $\begin{array}{l}\Delta H_{\text {rel }} \mathrm{CPCM} \\
\left(\mathrm{kJ} \mathrm{mol}^{-1}\right)^{c}\end{array}$ \\
\hline 2 & $2.5923(17)[0.74]$ & $2.628[0.73]$ & $2.629[0.76]$ & 0 \\
\hline 2 ' & $n / a$ & $2.974[0.33]$ & $2.820[0.49]$ & 15.3 \\
\hline 3 & $2.7104(8)[0.48]$ & $2.978[0.32]$ & $2.713[0.60]$ & $\mathbf{0}$ \\
\hline 3 ' & $n / a$ & $3.208[0.17]$ & $3.215[0.17]$ & 53.7 \\
\hline 3, & $n / a$ & $2.621[0.73]$ & $2.606[0.77]$ & 51.3 \\
\hline 3-Mes & $2.7244(9)[0.48]$ & $2.966[0.34]$ & $2.794[0.51]$ & $\mathbf{0}$ \\
\hline 3'-Mes & $n / a$ & $3.238[0.16]$ & $3.242[0.16]$ & 55.8 \\
\hline 4 & $3.191(1)[0.15]$ & $3.240[0.14]$ & $3.246[0.14]$ & $\mathbf{0}$ \\
\hline $4^{\prime}$ & $n / a$ & $2.679[0.62]$ & $2.638[0.68]$ & 153.7 \\
\hline 5 & $2.6199(8)[0.57]$ & $2.709[0.54]$ & $2.682[0.59]$ & $\mathbf{0}$ \\
\hline 6 & $2.659(2)[0.53]$ & $2.789[0.47]$ & $2.742[0.54]$ & $\mathbf{0}$ \\
\hline $6{ }^{\prime}$ & $n / a$ & $2.750[0.52]$ & $2.722[0.58]$ & 7.0 \\
\hline 7 & $2.9925(8)[0.29]$ & $3.069[0.27]$ & $3.057[0.29]$ & $\mathbf{0}$ \\
\hline 7' & $n / a$ & $2.799[0.46]$ & $2.737[0.54]$ & 15.5 \\
\hline 8 & $3.088(3)[0.25]$ & $3.167[0.22]$ & $3.185[0.22]$ & $\mathbf{0}$ \\
\hline 8 & $n / a$ & $2.994[0.35]$ & $2.892[0.44]$ & 58.2 \\
\hline 9 & $3.1247(16)[0.22]$ & $3.223[0.19]$ & $3.214[0.20]$ & $\mathbf{0}$ \\
\hline
\end{tabular}

${ }^{a} \mathrm{SDD} / 6-31 \mathrm{G}^{*}$ basis. ${ }^{b} \mathrm{SDD} / 6-31(+) \mathrm{G}^{*}$ basis, CPCM model (parameters of $\mathrm{CHCl}_{3}$ ). Computed enthalpy of isomers (marked with primes) relative to the observed species at the B3LYP/SDD/6-31(+)G*/CPCM level in $\mathrm{kJ} \mathrm{mol}^{-1}$. 


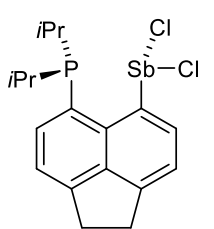

2' $(+15.3)$

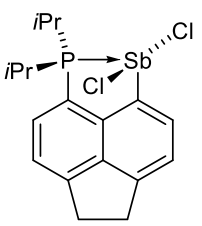

2

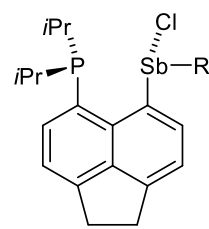

3' $\mathrm{R}=\mathrm{Ph}(+53.7)$

3'-Mes $R=$ Mes (+55.8)

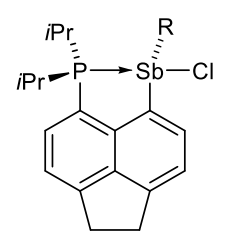

$3 \mathrm{R}=\mathrm{Ph}$

3-Mes $R=$ Mes

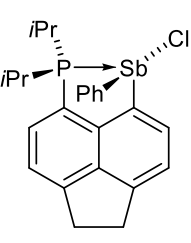

3"

$(+51.3)$

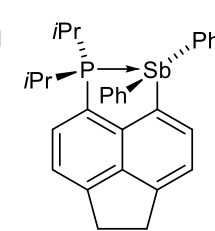

$4^{\prime}$

$(+153.7)$

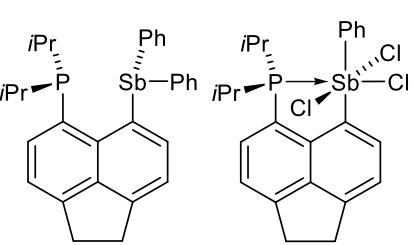

6

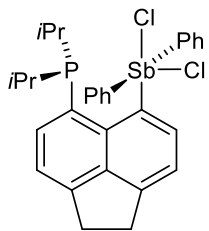

7 $(+15.5)$

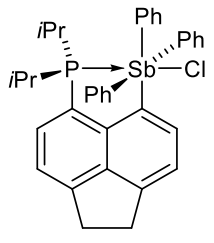

$8^{\prime}$ $(+58.2)$

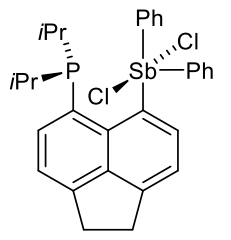

7

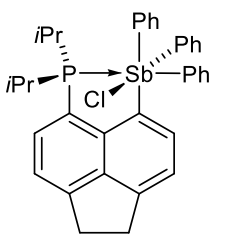

8

Figure 8: Compounds synthesised in this study and their higher lying computed isomers. Computed enthalpy of isomers (marked with primes) are relative to the observed species at the B3LYP/SDD/6-31(+)G*/CPCM level in $\mathrm{kJ} \mathrm{mol}^{-1}$.

The $\mathrm{P}-\mathrm{Sb}$ distances, related WBIs and relative enthalpies of selected isomers of compounds 2-4 and 6-8 (Figure 8) were computed and are shown in Table 3. The strongest $\mathrm{P}-\mathrm{Sb}$ interaction is found for $\mathbf{2}$, where it amounts to almost a full single bond (WBI exceeding 0.70). The isomer $2^{\prime}$ with a bent $\mathrm{Cl}-\mathrm{Sb}-\mathrm{Cl}$ moiety (angle $89.3^{\circ}$ ) has a longer $\mathrm{P}-\mathrm{Sb}$ distance and concomitantly, a smaller, but still substantial WBI of $c a$. 0.49. An even larger WBI of 0.60 is obtained for 3 (and 3-Mes, WBI 0.51). Also, the WBIs for the $\mathrm{Sb}-\mathrm{Cl}$ bonds trans to the phosphorus are much reduced (0.44 in 2', 0.24 in 3), indicating true multicentre bonding in these (type $\mathbf{Y}$ ) species.

In most cases unconstrained searches for localised MOs in Natural Bond Orbital $(\mathrm{NBO})^{[33]}$ analyses did not find any $\mathrm{Sb}-\mathrm{Cl}$ bonds. Instead chlorine atoms are almost invariably localised as $\mathrm{Cl}^{-}$ions (with four lone pairs), underscoring the highly polar nature of these bonds. The only exception to this was for the perchloroantimony compound $\mathbf{5}$, where the NBO analysis finds one $\mathrm{P}-\mathrm{Sb}$, one $\mathrm{Sb}-\mathrm{C}$ and four $\mathrm{Sb}-\mathrm{Cl}$ bonds, each with relatively low occupancies of 1.8 electrons (instead of the expected 2.0 electrons for a $2 c-2 e$ bond).

The weakest phosphorus-antimony interaction is found in 4 . Despite the long $\mathrm{P} \cdots \mathrm{Sb}$ distance around $3.2 \AA$ (the longest of all the compounds in this study), the WBI is still noticeable at 0.15 . This value is comparable to those of related systems such as Acenap(PiPr$\left.{ }_{2}\right)\left(\mathrm{SnPh}_{3}\right)$ or Acenap $(\mathrm{TePh})_{2}($ Acenap $=$ acenaphthene-5,6-diyl $)$, where the onset of the $3 \mathrm{c}-4 \mathrm{e}$ bonding between the formally non-bonded atoms has been shown through the sizable $J\left({ }^{31} \mathrm{P}-\right.$ $\left.{ }^{119} \mathrm{Sn}\right)$ or $J\left({ }^{125} \mathrm{Te}-{ }^{125} \mathrm{Te}\right)$ coupling constants. ${ }^{[32,34]}$ Unfortunately, the unfavourable properties 
of the NMR-active antimony isotopes $\left({ }^{121} \mathrm{Sb}\right.$ and $\left.{ }^{123} \mathrm{Sb}\right)$, in particular their high quadrupolar moments, prevent the use of direct $\mathrm{P}-\mathrm{Sb}$ NMR probe in this series. On the other hand, compound 4 displays large magnitude $(40.1 \mathrm{~Hz})$ of a ${ }^{31} \mathrm{P}-{ }^{13} \mathrm{C}$ coupling involving the ipsocarbon from a phenyl group on the antimony atom (atom C13 in Figure 2, hence formally $\left.{ }^{5 t s} J_{\mathrm{CP}}\right)$. This is likely to involve a strong through space component, indicating significant overlap of orbitals on $\mathrm{P}$ and $\mathrm{Sb}$ atoms.

The $\mathrm{Sb}^{\mathrm{V}}$ compounds (5-9) all show significant $\mathrm{P}-\mathrm{Sb}$ interactions. These are particularly strong when a chlorine atom is located trans to the phosphorus atom, as in $\mathbf{5}$ and 6 (WBIs exceeding 0.5), but are still substantial with phenyl groups trans to phosphorus, as in 7-9 (WBIs $c a$. 0.2-0.3). The WBI data for the corresponding hypervalent tin compounds Acenap $\left(\mathrm{P} i P r_{2}\right)\left(\mathrm{SnPh}_{n} \mathrm{Cl}_{3-\mathrm{n}}\right)$ in a previous study were found to be around $0.3-0.4$ for the mixed $\mathrm{Ph} / \mathrm{Cl}$ substituents (where chlorine is always trans to phosphorus), and 0.12 for the $\mathrm{SnPh}_{3}$ derivative. ${ }^{[32]}$ The covalent multicentre character is thus more pronounced for the $\mathrm{P}-\mathrm{Sb}$ than for the P-Sn motif.

For the mixed $\mathrm{Ph} / \mathrm{Cl}$ compounds (6, 7 and $\mathbf{8})$, the computed stereoisomers (6', 7' and 8 ' - see Figure 8) are all energetically disfavoured with $\Delta H_{\text {rel }}$ lying between $c a .7$ and $60 \mathrm{~kJ}$ $\mathrm{mol}^{-1}$ higher in energy (see Table 3). The B3LYP/CPCM WBIs are plotted against the optimised $\mathrm{P}-\mathrm{Sb}$ distances in Figure 9, illustrating the expected inverse relationship. 


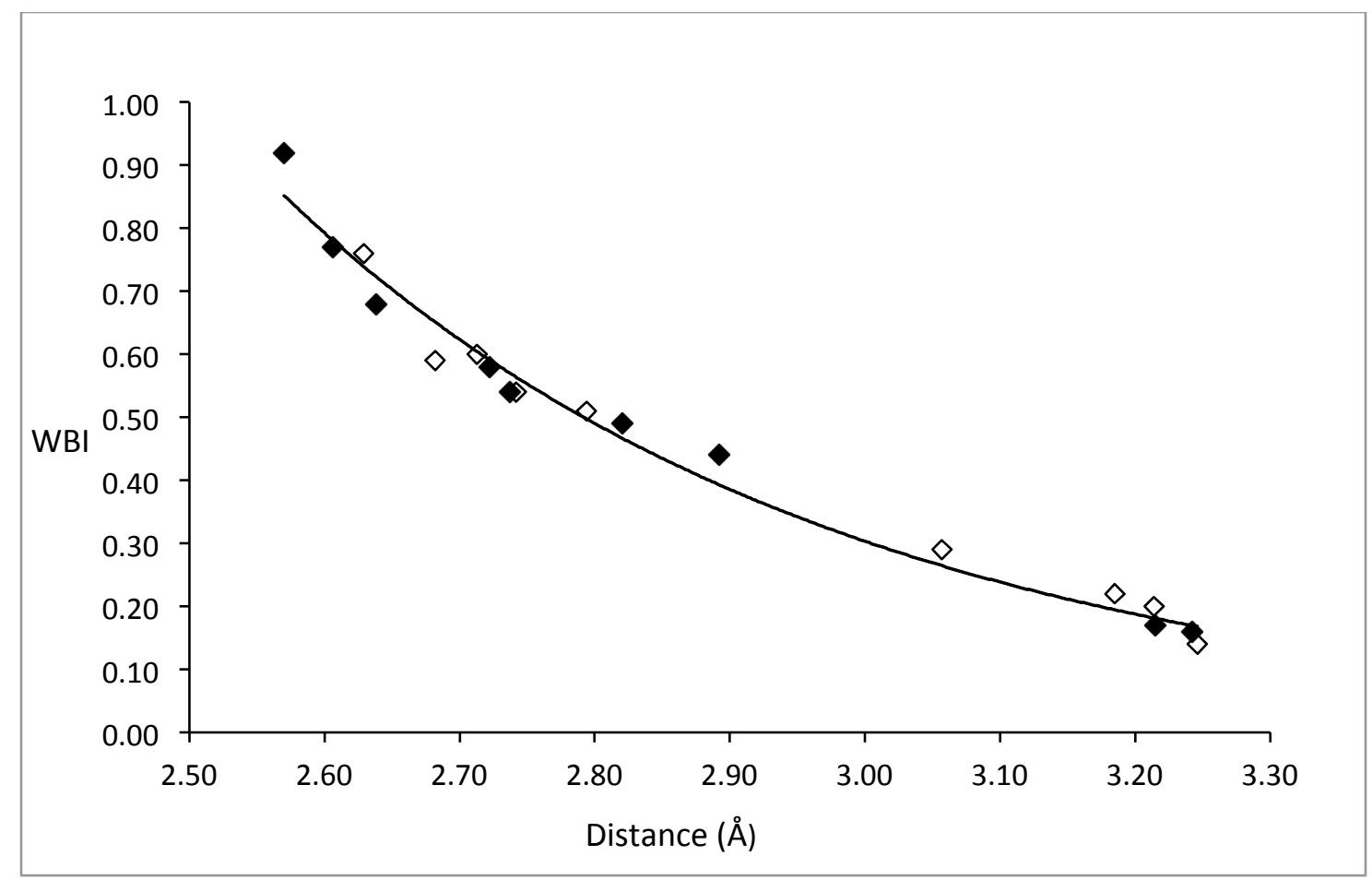

Figure 9: Plot of computed $\mathrm{P}-\mathrm{Sb}$ WBIs against optimised $\mathrm{P}-\mathrm{Sb}$ distances; data taken from Table 3 (B3LYP/CPCM level). Unfilled squares represent compounds 2-9 and filled squares represent calculated stereoisomers (2', 3', 3', 3'-Mes, 4', 6', 7' and 8'). Included is also a hypothetical compound $\mathrm{Me}_{2} \mathrm{P}-\mathrm{SbMe}_{2}$ with a full formal single bond (filled square, top left). An exponential fit to all points is included to guide the eye.

As mentioned earlier, compounds with chlorine atoms trans to the phosphorus atom were more affected by the environment used to model them owing to the resonance $\mathrm{P}-\mathrm{Sb}-\mathrm{Cl}$ $\leftrightarrow \mathrm{P}^{+}-\mathrm{Sb}^{\cdots} \mathrm{Cl}^{-}$. In order to gain further insight into this, the structure of $\mathbf{3}$ was optimised using a set of modelling solvents with varying polarity and was compared to the experimental X-ray structure. The results of these computations are shown in Table 4.

Table 4: Medium effects on $\mathrm{P}-\mathrm{Sb}$ and $\mathrm{Sb}-\mathrm{Cl}$ bond distances $(\AA)$ calculated for compound 3 at the B3LYP/SDD level. WBIs obtained at the same level are given in square parentheses.

\begin{tabular}{llll}
\hline Medium & Basis set $^{\boldsymbol{a}}$ & $\boldsymbol{d}_{\mathbf{P}-\mathbf{S b}}(\mathbf{W B I})$ & $\boldsymbol{d}_{\mathbf{S b}-\mathrm{Cl}}(\mathbf{W B I})$ \\
\hline Crystal (X-ray) & $\mathrm{n} / \mathrm{a}$ & $2.710[0.48]$ & $2.680[0.46]$ \\
Gas & $6-31 \mathrm{G}^{*}$ & $2.978[0.32]$ & $2.533[0.57]$ \\
$\mathbf{G a s}$ & $6-31+\mathrm{G}^{*}$ & $2.966[0.33]$ & $2.550[0.56]$ \\
$\mathbf{C H C l}_{\mathbf{3}}{ }^{\boldsymbol{b}}$ & $6-31+\mathrm{G}^{*}$ & $2.800[0.50]$ & $2.753[0.37]$ \\
$\mathbf{M e C N}^{\boldsymbol{b}}$ & $6-31+\mathrm{G}^{*}$ & $2.721[0.59]$ & $2.935[0.26]$ \\
$\mathbf{H}_{\mathbf{2}} \mathbf{O}^{\boldsymbol{b}}$ & $6-31+\mathrm{G}^{*}$ & $2.713[0.60]$ & $2.959[0.24]$ \\
\hline
\end{tabular}

${ }^{a} \mathrm{SDD}$ on Sb and 6-31G* elsewhere. ${ }^{b}$ CPCM model. 
Regardless of the polarity of the modelling solvent $\left(\mathrm{CHCl}_{3}, \mathrm{MeCN}, \mathrm{H}_{2} \mathrm{O}\right)$, the $\mathrm{P}-\mathrm{Sb}$ bond length in $\mathbf{3}$ does not vary too dramatically from the distance observed in the X-ray structure (largest change is $c a$. $0.1 \AA$ ). However, the $\mathrm{P}-\mathrm{Sb}$ distance does show a large increase (ca. $0.26 \AA$ ) when modelled without solvent (i.e. in gas phase). The $\mathrm{Sb}-\mathrm{Cl}$ bond length depends heavily on the medium in which the optimisation is modelled. In highly polar solvents, such as water and acetonitrile, the $\mathrm{Sb}-\mathrm{Cl}$ distance increases by $c a .0 .28 \AA$ as compared to the $\mathrm{X}$ ray structure with the computed WBIs also showing a complementary change (Scheme 2 and Table 4).<smiles>CC(C)P(c1c(SCl)ccc2c1-c1c(ccc3c1CCC3)CC2)C(C)C</smiles>

3 (gas phase)<smiles>CC(C)[PH](O)(c1ccc2c3c(ccc(Cl)c13)CC2)C(C)C</smiles>

3 (X-ray)

$$
\mathrm{d}_{\mathrm{P}-\mathrm{Sb}} 2.710(0.48)
$$$$
\mathrm{d}_{\mathrm{Sb}-\mathrm{Cl}} 2.680(0.46)
$$<smiles>CC(C)P(C)(=O)c1ccc2c3c(ccc(C(C)(C)C)c13)CC2</smiles><smiles>[13CH3][14CH3]</smiles>

$\mathrm{d}_{\mathrm{P}-\mathrm{Sb}} 2.713(0.60)$

$\mathrm{d}_{\mathrm{Sb}-\mathrm{Cl}} 2.959(0.24)$

Scheme 2: Structures of 3 modelled in different media with $\mathrm{P}-\mathrm{Sb}$ and $\mathrm{Sb}-\mathrm{Cl}$ distances given along with their corresponding WBIs (in parentheses).

In the gas phase (using both $6-31 \mathrm{G}^{*}$ and $6-31+\mathrm{G}^{*}$ basis) the $\mathrm{P}-\mathrm{Sb}$ distance is long enough to be considered a non-bonding interaction, and the $\mathrm{Sb}-\mathrm{Cl}$ bond length is short (of typical covalent length). The other extreme of this is using the CPCM calculations for water and acetonitrile in which the $\mathrm{P}-\mathrm{Sb}$ distance is shorter (WBI reaching 0.60 ), yet the $\mathrm{Sb} \cdots \mathrm{Cl}$ distance is long enough for the compound to be consider a phosphonium salt with a chloride counter ion. The observed X-ray structure is middle ground, with WBIs in between those of the two extremes (Scheme 2). This short study serves to show the effect the solvating medium has on the compound with tendency to ionise in highly polar medium.

\section{Conclusion}

Two distinct comprehensive series of intramolecular phosphine complexes with antimony-centred groups of varied Lewis acidity were synthesised and fully characterised. The presence of the supporting backbone in these species allows observation of the full scale of the $\mathrm{P}-\mathrm{Sb}$ interaction, from strongly bonding to non-bonding (i.e. repulsive). The structural and computational data demonstrate the ambiguity of the assignment of a bond as a standard 
covalent or strong dative, and also highlights the existence of situations in which description of the interaction as bonding or non-bonding is somehow arbitrary.

No fundamental geometry change (rehybridisation) is observed within the series of $\mathrm{Sb}^{\mathrm{V}}$ compounds, with the coordination environment of the $\mathrm{Sb}$ acceptor remaining octahedral throughout. The two extremes, compounds $\mathbf{5}$ and $\mathbf{9}$, can be described as $\mathrm{P}-\mathrm{Sb}$ covalently bonded (5) and non-bonded (9). Within this series the $\mathrm{P}-\mathrm{Sb}$ bond length increases by 19\%, while WBI drops from 0.57 to 0.22 . Despite the Lewis acidity of the $\mathrm{Sb}^{\mathrm{V}}$-centred groups being modified gradually (in regular steps) by varying the ratio of $\mathrm{Cl}$ and $\mathrm{Ph}$ substituents, the $\mathrm{P}-\mathrm{Sb}$ bond strength trend within the series is not smooth. A sudden structural change is observed between 6 and 7, with the P-Sb distance being elongated by 12\%, and WBI dropping from 0.53 to 0.29 on replacing just one of the chlorine groups with phenyl group. This can be considered as the dividing line between the bonding and non-bonding (i.e. repulsive) interaction, although this division is somewhat arbitrary as the WBI in $\mathbf{7}$ is still $54 \%$ of that in 6 , and certainly remains significant. The $\mathrm{P}-\mathrm{Sb}$ contacts in 6 and 7 are both strongly sub-van der Waals (64 and $72 \%$ of respective $\Sigma_{\mathrm{VdW}}$ of $4.15 \AA$ ). However, the relatively sudden drop in WBI between 6 and 7 serves as an illustration of non-linear relationship of Lewis acidity/Lewis basicity difference and strength of dative interaction.

Interestingly, compounds 5-9 represent the first structurally characterised electroneutral phosphine-stiborane complexes. The support of the peri-backbone is likely to contribute to their (thermal) stability. Several examples of using peri-substitution to stabilise unusual hypervalent species has been reported, ${ }^{[35]}$ in addition to examples of supporting lowvalent pnictogen motifs. ${ }^{[15,36]}$

Significant structural variety is observed in the $\mathrm{Sb}^{\mathrm{III}}$ series. As above, the bonding varies from a strong covalent $\mathrm{P}-\mathrm{Sb}$ bond in $\mathbf{2}$, to essentially non-bonding interaction in $\mathbf{4}$. The $\mathrm{P}-\mathrm{Sb}$ distance in $\mathbf{2}$ is within the usual range of $\lambda^{3} \mathrm{P}-\lambda^{3} \mathrm{Sb}$ bonds, which implies a strong (i.e. "normal" rather than dative) bond is present. This is further supported by the fact that 2 attains a fundamentally different structure compared to the electronically closely related species 3 and 3-Mes, which display dative bonds of varying strength with significant 3c-4e component. 


\section{Experimental}

\section{General Considerations}

All reactions and manipulations were carried out under an atmosphere of nitrogen using standard Schlenk techniques or under an argon atmosphere in a Saffron glove box. Dry solvents were either collected from an MBraun Solvent Purification System, or dried and stored according to common procedures. ${ }^{[37]}$ Compound $\mathbf{1}$ was prepared according to the published procedure. ${ }^{[5 b]}$ Antimony trichloride was purchased from Sigma Aldrich and further purified by vacuum sublimation and stored under argon in a glovebox. Antimony reagents used to prepare compounds $\mathbf{3}, \mathbf{3 - M e s ,}, \mathbf{4}, \mathbf{7}, \mathbf{8}$ and $\mathbf{9}$ were synthesised using modified literature procedures, described in the supplementary information. ${ }^{[38]}$ Other chemicals were purchased from Acros Organics or Sigma Aldrich and used as received. All new compounds were fully characterized by ${ }^{1} \mathrm{H},{ }^{13} \mathrm{C}\left\{{ }^{1} \mathrm{H}\right\}$ and ${ }^{31} \mathrm{P}\left\{{ }^{1} \mathrm{H}\right\}$ NMR, as well as ${ }^{1} \mathrm{H}\left\{{ }^{31} \mathrm{P}\right\},{ }^{31} \mathrm{P}\left({ }^{1} \mathrm{H}\right.$ coupled $), \mathrm{H}-\mathrm{H}$ DQF COSY, H-C HSQC, H-C HMBC and H-P HMBC. Measurements were performed at $25^{\circ} \mathrm{C}$ using either a Bruker Avance II $400 \mathrm{MHz}$ or Bruker Avance III $500 \mathrm{MHz}$ spectrometer. $85 \% \mathrm{H}_{3} \mathrm{PO}_{4}$ was used as an external standard for ${ }^{31} \mathrm{P}$ NMR; ${ }^{1} \mathrm{H}$ and ${ }^{13} \mathrm{C}$ NMR shifts are relative to $\mathrm{Me}_{4} \mathrm{Si}$, residual solvent peaks were used for calibration $\left(\mathrm{CHCl}_{3} \delta_{\mathrm{H}} 7.26, \delta_{\mathrm{C}} 77.2\right.$ ppm, $\left.\mathrm{CH}_{2} \mathrm{Cl}_{2} \delta_{\mathrm{H}} 5.36, \delta_{\mathrm{C}} 53.5 \mathrm{ppm}, \mathrm{C}_{6} \mathrm{H}_{6} \delta_{\mathrm{H}} 7.16, \delta_{\mathrm{C}} 128.1 \mathrm{ppm}\right)$. Raman and IR spectra were collected on a Perkin Elmer 2000 IR/Raman FT spectrometer with a dipole pumped NdYAG near-IR excitation laser. Mass Spectrometry was performed using a Micromass LCT (ES) and a Micromass GCT (EI) at the University of St Andrews or at the EPSRC UK National Mass Spectrometry Facility in Swansea using a Finnigan MAT 95 XP (EI) or a Thermofisher LTQ Orbitrap XL (APCI). Elemental Analysis (C, H and N) was performed by the Elemental Analysis Service of London Metropolitan University. "In vacuo" refers to a pressure of ca. 10 Pa. 


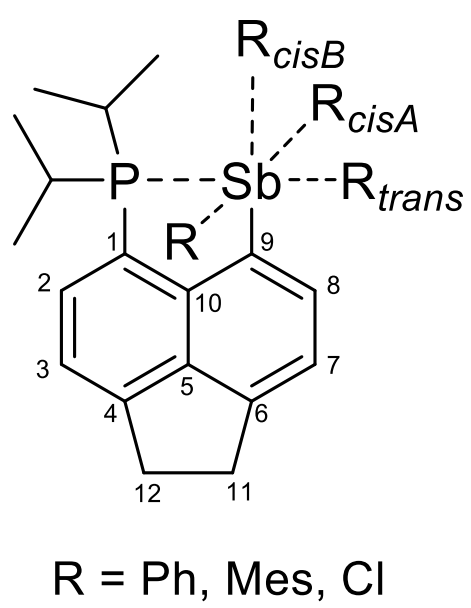

Figure 10: NMR numbering scheme for compounds 2-9.

iPr $\mathbf{P r}_{2} \mathbf{P}-\mathbf{A c e}-\mathrm{SbCl}_{\mathbf{2}}$ (2): To a cooled $\left(-78^{\circ} \mathrm{C}\right)$, rapidly stirring solution of $\mathbf{1}$ (1.30 g, $\left.3.72 \mathrm{mmol}\right)$ in diethyl ether $(20 \mathrm{~mL}), n$-butyllithium $(1.50 \mathrm{~mL}$ of $2.5 \mathrm{M}$ solution in hexanes, $3.72 \mathrm{mmol})$ was added drop wise over $1 \mathrm{~h}$. The solution was then left to stir for $2 \mathrm{~h}$ at the same temperature. The resulting suspension was then added in small batches via cannula to a rapidly stirring solution of antimony trichloride $(840 \mathrm{mg}, 3.72 \mathrm{mmol})$ in diethyl ether (100 $\mathrm{mL}$ ) that had been pre-cooled to $-78^{\circ} \mathrm{C}$. The solution was left to stir and warm to room temperature overnight. The solid was collected from the white suspension by filtration and was rapidly washed with degassed water $(25 \mathrm{~mL})$. After drying in vacuo, pure 2 was obtained as a white powder (1.56 g, 91\%) (M. p. $188^{\circ} \mathrm{C}$ with decomposition). Crystals suitable for Xray diffraction were obtained from dichloromethane at $0^{\circ} \mathrm{C}$.

${ }^{1} \mathbf{H}$ NMR $\left(500.1 \mathrm{MHz}, \mathrm{CDCl}_{3}\right) \delta=7.96\left(\mathrm{~d},{ }^{3} J(\mathrm{H}, \mathrm{H})=7.1 \mathrm{~Hz}, 1 \mathrm{H} ; \mathrm{H}-8\right), 7.91$ (m, 1H; H-2), $7.59\left(\mathrm{~d},{ }^{3} J(\mathrm{H}, \mathrm{H})=7.2 \mathrm{~Hz}, 1 \mathrm{H} ; \mathrm{H}-7\right), 7.37\left(\mathrm{~d},{ }^{3} J(\mathrm{H}, \mathrm{H})=7.1 \mathrm{~Hz}, 1 \mathrm{H} ; \mathrm{H}-3\right), 3.54-3.45(\mathrm{~m}, 4 \mathrm{H}$; $\left.\mathrm{CH}_{2}\right), 2.91\left(\mathrm{~h},{ }^{3} J(\mathrm{H}, \mathrm{H})=7.1 \mathrm{~Hz}, 1 \mathrm{H} ; \mathrm{CH}\left(\mathrm{CH}_{3}\right)_{2}\right), 2.74\left(\mathrm{dh},{ }^{3} J(\mathrm{H}, \mathrm{H})=7.2,{ }^{2} J(\mathrm{H}, \mathrm{P})=4.0 \mathrm{~Hz}\right.$, $\left.1 \mathrm{H} ; \mathrm{CH}\left(\mathrm{CH}_{3}\right)_{2}\right), 1.68\left(\mathrm{~m}, 12 \mathrm{H} ; \mathrm{CH}_{3}\right) ;{ }^{13} \mathbf{C}\left\{{ }^{1} \mathbf{H}\right\} \mathbf{N M R}\left(125.8 \mathrm{MHz}, \mathrm{CDCl}_{3}\right) \delta=152.5(\mathrm{~s} ; \mathrm{qC}-$ 6), 149.9 (s; qC-4), 142.5 (d, $\left.{ }^{2} J(\mathrm{C}, \mathrm{P})=11.6 \mathrm{~Hz} ; \mathrm{qC}-10\right), 140.2$ (s; qC-5), 139.2 (s; C-8), $133.8\left(\mathrm{~d},{ }^{2} J(\mathrm{C}, \mathrm{P})=6.3 \mathrm{~Hz}\right.$; C-2), 131.5 (s; qC-9), 121.9 (s; C-7), 121.4 (s; C-3), 30.6 (s; $\left.\mathrm{CH}_{3}\right), 30.5\left(\mathrm{~s} ; \mathrm{CH}_{3}\right), 26.3\left(\mathrm{~d},{ }^{1} J(\mathrm{C}, \mathrm{P})=22.7 \mathrm{~Hz} ; \mathrm{CH}\left(\mathrm{CH}_{3}\right)_{2}\right), 19.8\left(\mathrm{~s} ; \mathrm{CH}_{3}\right), 18.7\left(\mathrm{~s} ; \mathrm{CH}_{3}\right)$; ${ }^{31} \mathbf{P}\left\{{ }^{1} \mathbf{H}\right\}$ NMR $\left(202.5 \mathrm{MHz}, \mathrm{CDCl}_{3}\right) \delta=51.0(\mathrm{~s})$; IR $\left(\mathrm{KBr} \operatorname{disc}, \mathrm{cm}^{-1}\right) v=2925 \mathrm{~m}\left(v_{\mathrm{C}-\mathrm{H}}\right)$, 1638s , 1460m, 1361m, 1030m, 849s, 714m, 326m, 279s, 249s; Raman (glass capillary, cm ${ }^{-}$ $\left.{ }^{1}\right) v=3057 \mathrm{~m}\left(v_{\mathrm{Ar}-\mathrm{H}}\right), 2929 \mathrm{vs}\left(v_{\mathrm{C}-\mathrm{H}}\right), 1596 \mathrm{~s}, 1442 \mathrm{~s}, 1411 \mathrm{~s}, 1361 \mathrm{~m}, 1339 \mathrm{~s}, 583 \mathrm{vs}\left(\beta_{\mathrm{C}-\mathrm{H}}\right), 554 \mathrm{~m}$, 496w, 340s ( $\left.v_{\mathrm{Sb}-\mathrm{Cl}}\right)$, and 251s; MS (ES+): $m / z(\%) 424.72(100)$ [M-Cl]; Elemental Analysis Calcd (\%) for $\mathrm{C}_{18} \mathrm{H}_{22} \mathrm{PSbCl}_{2}$ (462.01 $\mathrm{g} \mathrm{mol}^{-1}$ ): C 46.79, H 4.80; Found: C 46.49, H 4.91. 


\section{iPr 2 P-Ace-Sb(Ph)Cl (3):}

To a cooled $\left(-78^{\circ} \mathrm{C}\right)$, rapidly stirring solution of $\mathbf{1}(4.00 \mathrm{~g}, 11.45 \mathrm{mmol})$ in diethyl ether (100 $\mathrm{mL}$ ), $n$-butyllithium (4.60 $\mathrm{mL}$ of $2.5 \mathrm{M}$ solution in hexanes, $11.45 \mathrm{mmol}$ ) was added over a period of $1 \mathrm{~h}$ and the mixture was left to stir for two $\mathrm{h}$ at the same temperature. To this a solution of dichlorophenylantimony $(3.10 \mathrm{~g}, 11.45 \mathrm{mmol})$ in diethyl ether $(30 \mathrm{~mL})$ was added dropwise over 30 min whilst maintaining the reaction at $-78{ }^{\circ} \mathrm{C}$. After addition, the reaction mixture was left to stir and warm up to room temperature overnight. The solid was collected from the pale yellow suspension by filtration and washed rapidly with degassed water (25 $\mathrm{mL})$ to give a white powder (4.79 g, 83\%) (M. p. $270{ }^{\circ} \mathrm{C}$ with decomposition). Crystals suitable for X-ray diffraction were grown from chloroform at $0^{\circ} \mathrm{C} .{ }^{1} \mathbf{H}$ NMR $(500.1 \mathrm{MHz}$, $\left.\mathrm{CDCl}_{3}\right) \delta=9.18\left(\mathrm{~d},{ }^{3} J(\mathrm{H}, \mathrm{H})=7.1 \mathrm{~Hz}, 1 \mathrm{H} ; \mathrm{H}-8\right), 7.64\left(\mathrm{~d},{ }^{3} J(\mathrm{H}, \mathrm{H})=7.2 \mathrm{~Hz}, 1 \mathrm{H} ; \mathrm{H}-7\right), 7.60$ (pseudo dd, $\left.{ }^{3} J(\mathrm{H}, \mathrm{P})=7.0,{ }^{3} J(\mathrm{H}, \mathrm{H})=7.0 \mathrm{~Hz}, 1 \mathrm{H} ; \mathrm{H}-2\right), 7.51-7.47(\mathrm{~m}, 2 \mathrm{H} ; o-\mathrm{H}), 7.40\left(\mathrm{~d},{ }^{3} J\right.$ $(\mathrm{H}, \mathrm{H})=7.1 \mathrm{~Hz}, 1 \mathrm{H} ; \mathrm{H}-3), 7.24-7.16(\mathrm{~m}, 3 \mathrm{H} ; m-\mathrm{H} / p-\mathrm{H}), 3.52\left(\mathrm{~s}, 4 \mathrm{H} ; \mathrm{CH}_{2}\right), 2.52-2.41(\mathrm{~m}$, $1 \mathrm{H} ; 1 \times \mathrm{CH}), 2.39-2.29(\mathrm{~m}, 1 \mathrm{H} ; 1 \times \mathrm{CH}), 1.22\left(\mathrm{dd},{ }^{3} J(\mathrm{H}, \mathrm{P})=17.0,{ }^{3} J(\mathrm{H}, \mathrm{H})=7.0 \mathrm{~Hz}, 3 \mathrm{H} ; 1\right.$ $\left.\times \mathrm{CH}_{3}\right), 1.12\left(\mathrm{dd},{ }^{3} J(\mathrm{H}, \mathrm{P})=13.7,{ }^{3} J(\mathrm{H}, \mathrm{H})=7.0 \mathrm{~Hz}, 3 \mathrm{H} ; 1 \times \mathrm{CH}_{3}\right), 0.80\left(\mathrm{dd},{ }^{3} J(\mathrm{H}, \mathrm{P})=17.3\right.$, $\left.{ }^{3} J(\mathrm{H}, \mathrm{H})=7.0 \mathrm{~Hz}, 3 \mathrm{H} ; 1 \times \mathrm{CH}_{3}\right), 0.45\left(\mathrm{dd},{ }^{3} J(\mathrm{H}, \mathrm{P})=15.0,{ }^{3} J(\mathrm{H}, \mathrm{H})=7.1 \mathrm{~Hz}, 3 \mathrm{H} ; 1 \times \mathrm{CH}_{3}\right)$; ${ }^{13} \mathbf{C}\left\{{ }^{1} \mathbf{H}\right\}$ NMR $\left(125.8 \mathrm{MHz}, \mathrm{CDCl}_{3}\right) \delta=152.1(\mathrm{~s} ; \mathrm{qC}-4), 148.0(\mathrm{~s} ; \mathrm{qC}-6), 144.2\left(\mathrm{~d},{ }^{2} J(\mathrm{C}, \mathrm{P})=\right.$ $28.7 \mathrm{~Hz} ; \mathrm{qC}-10), 140.6$ (s; ipso), $140.4\left(\mathrm{~d},{ }^{3} J(\mathrm{C}, \mathrm{P})=3.6 \mathrm{~Hz} ; \mathrm{C}-8\right), 140.1$ (d, ${ }^{3} J(\mathrm{C}, \mathrm{P})=2.2$ $\mathrm{Hz}$; qC-5), $135.4\left(\mathrm{~d},{ }^{3} J(\mathrm{C}, \mathrm{P})=1.8 \mathrm{~Hz} ; o-\mathrm{C}\right), 135.1\left(\mathrm{~d},{ }^{2} J(\mathrm{C}, \mathrm{P})=5.6 \mathrm{~Hz} ; \mathrm{qC}-9\right), 133.4\left(\mathrm{~d},{ }^{2} J\right.$ $(\mathrm{C}, \mathrm{P})=3.8 \mathrm{~Hz} ; \mathrm{C}-2), 128.9(\mathrm{~s} ; m-\mathrm{C}), 128.6(\mathrm{~s} ; p-\mathrm{C}), 122.5\left(\mathrm{~d},{ }^{1} J(\mathrm{C}, \mathrm{P})=20.8 \mathrm{~Hz} ; \mathrm{qC}-1\right)$, $122.1(\mathrm{~s} ; \mathrm{C}-7), 119.5\left(\mathrm{~d} ;{ }^{3} J(\mathrm{C}, \mathrm{P})=4.9 \mathrm{~Hz} ; \mathrm{C}-3\right), 30.9$ (s; C-11/12), 30.2 (s; C-11/12), 24.7 (d, $\left.{ }^{1} J(\mathrm{C}, \mathrm{P})=4.5 \mathrm{~Hz} ; 1 \times \mathrm{CH}\right), 24.3\left(\mathrm{~d},{ }^{1} J(\mathrm{C}, \mathrm{P})=14.0 \mathrm{~Hz} ; 1 \times \mathrm{CH}\right), 19.1\left(\mathrm{~d},{ }^{2} J(\mathrm{C}, \mathrm{P})=4.7 \mathrm{~Hz} ; 1\right.$ $\left.\times \mathrm{CH}_{3}\right), 18.0\left(\mathrm{~d},{ }^{2} J(\mathrm{C}, \mathrm{P})=5.0 \mathrm{~Hz} ; 1 \times \mathrm{CH}_{3}\right), 17.9\left(\mathrm{~d},{ }^{2} J(\mathrm{C}, \mathrm{P})=5.9 \mathrm{~Hz} ; 1 \times \mathrm{CH}_{3}\right), 17.1\left(\mathrm{~d},{ }^{2} J\right.$ $\left.(\mathrm{C}, \mathrm{P})=1.9 \mathrm{~Hz} ; 1 \times \mathrm{CH}_{3}\right) ;{ }^{31} \mathbf{P}\left\{{ }^{1} \mathbf{H}\right\} \mathbf{N M R}\left(202.5 \mathrm{MHz}, \mathrm{CDCl}_{3}\right) \delta=1.5(\mathrm{~s}) ; \mathbf{I R}\left(\mathrm{KBr} \operatorname{disc}, \mathrm{cm}^{-}\right.$ $\left.{ }^{1}\right) v=3049 \mathrm{~m}, 2966 \mathrm{~m}, 2930 \mathrm{~m}, 2364 \mathrm{w}, 1637 \mathrm{vs}, 1594 \mathrm{vs}, 1478 \mathrm{~s}, 1432 \mathrm{~s}, 1353 \mathrm{~s}, 1256 \mathrm{~s}, 1158 \mathrm{~m}$, 1068m, 1021m, 998m, 930w, 847vs, 820s, 744vs, 697s, 648m, 585m, 453m, 340s; Raman (glass capillary, $\left.\mathrm{cm}^{-1}\right) v=3049 \mathrm{~s}\left(v_{\mathrm{Ar}-\mathrm{H}}\right), 2920 \mathrm{~s}, 2884 \mathrm{~s}\left(v_{\mathrm{C}-\mathrm{H}}\right), 1594 \mathrm{~m}, 1576 \mathrm{~m}, 1441 \mathrm{~m}, 1414$, $1343 \mathrm{~s}, 1001 \mathrm{vs}, 823 \mathrm{~m}, 657 \mathrm{~s}, 587 \mathrm{~s}, 548 \mathrm{~m}, 259 \mathrm{vs}\left(\mathrm{v}_{\mathrm{Sb}-\mathrm{Cl}}\right), 184 \mathrm{vs} ; \mathrm{MS}(\mathrm{ES}+): \mathrm{m} / z(\%) 467.09$ (100) [M-Cl]; HRMS (ES+): $m / z$ : Calcd. for $\mathrm{C}_{24} \mathrm{H}_{27} \mathrm{PSb}$ : 467.0889, found 467.0872.

$i \operatorname{Pr}_{2}$ P-Ace-Sb(Mes)Cl (3-Mes): To a cooled $\left(-78^{\circ} \mathrm{C}\right)$, rapidly stirring solution of 1 (1.00 g, $2.9 \mathrm{mmol})$ in diethyl ether $(25 \mathrm{~mL}), n$-butyllithium $(1.15 \mathrm{~mL}$ of $2.5 \mathrm{M}$ solution in hexanes, $2.9 \mathrm{mmol}$ ) was added over a period of $1 \mathrm{~h}$ and the mixture was left to stir for $2 \mathrm{~h}$ at the same temperature. To this a solution of dichloromesitylantimony $(0.89 \mathrm{~g}, 2.9 \mathrm{mmol})$ in diethyl 
ether $(15 \mathrm{~mL})$ was added over $30 \mathrm{~min}$ whilst maintaining the reaction at $-78{ }^{\circ} \mathrm{C}$. After addition, the reaction mixture was left to stir and warm up to room temperature with rapid stirring overnight. The solid was collected from the pale yellow suspension by filtration and washed rapidly with degassed water $(25 \mathrm{~mL})$ to give a white powder $(1.20 \mathrm{~g}, 77 \%)$ (M. p. $236{ }^{\circ} \mathrm{C}$ with decomposition). Crystals suitable for X-ray diffraction were grown from chloroform at ambient conditions. ${ }^{1} \mathbf{H}$ NMR $\left(500.1 \mathrm{MHz}^{\mathrm{CDCl}} \mathrm{CD}_{3} \delta=9.25\left(\mathrm{~d},{ }^{3} J(\mathrm{H}, \mathrm{H})=7.2\right.\right.$ $\mathrm{Hz}, 1 \mathrm{H} ; \mathrm{H}-8), 7.65$ (pseudo dd, $\left.{ }^{3} J(\mathrm{H}, \mathrm{P})=7.0,{ }^{3} J(\mathrm{H}, \mathrm{H})=7.0 \mathrm{~Hz}, 1 \mathrm{H} ; \mathrm{H}-2\right), 7.56\left(\mathrm{~d},{ }^{3} J(\mathrm{H}, \mathrm{H})\right.$ $=7.2 \mathrm{~Hz}, 1 \mathrm{H} ; \mathrm{H}-7), 7.37\left(\mathrm{~d},{ }^{3} J(\mathrm{H}, \mathrm{H})=7.0 \mathrm{~Hz}, 1 \mathrm{H} ; \mathrm{H}-3\right), 6.84(\mathrm{~s}, 1 \mathrm{H} ;$ Mes-CH), $6.65(\mathrm{~s}, 1 \mathrm{H}$; Mes-CH), 3.50 (br s, 4H; $\mathrm{CH}_{2}$ ), $2.83\left(\mathrm{~s}, 3 \mathrm{H} ; o-\mathrm{CH}_{3}\right), 2.44-2.37(\mathrm{~m}, 1 \mathrm{H} ; 1 \times \mathrm{CH}), 2.36-2.28$ $(\mathrm{m}, 1 \mathrm{H} ; 1 \times \mathrm{CH}), 2.20\left(\mathrm{~s}, 3 \mathrm{H} ; o-\mathrm{CH}_{3}\right), 1.90\left(\mathrm{~s}, 3 \mathrm{H} ; p-\mathrm{CH}_{3}\right), 1.23\left(\mathrm{dd},{ }^{3} J(\mathrm{H}, \mathrm{P})=16.9,{ }^{3} J\right.$ $\left.(\mathrm{H}, \mathrm{H})=7.0 \mathrm{~Hz}, 3 \mathrm{H} ; 1 \times \mathrm{CH}_{3}\right), 1.04\left(\mathrm{dd},{ }^{3} J(\mathrm{H}, \mathrm{P})=13.7,{ }^{3} \mathrm{~J}(\mathrm{H} . \mathrm{H})=7.0 \mathrm{~Hz}, 3 \mathrm{H} ; 1 \times \mathrm{CH}_{3}\right)$, $0.77\left(\mathrm{dd},{ }^{3} J(\mathrm{H}, \mathrm{P})=17.0,{ }^{3} J(\mathrm{H}, \mathrm{H})=7.0 \mathrm{~Hz}, 3 \mathrm{H} ; 1 \times \mathrm{CH}_{3}\right), 0.62\left(\mathrm{dd},{ }^{3} J(\mathrm{H}, \mathrm{P})=14.9,{ }^{3} J(\mathrm{H}, \mathrm{H})\right.$ $\left.=7.0 \mathrm{~Hz}, 3 \mathrm{H} ; 1 \times \mathrm{CH}_{3}\right) ;{ }^{13} \mathbf{C}\left\{{ }^{1} \mathbf{H}\right\} \mathbf{N M R}\left(125.8 \mathrm{MHz} \mathrm{CDCl}_{3}\right) \delta=151.9$ (s; qC-4), $147.5(\mathrm{~s}$; qC-6), 146.7 (s; qC-p-Mes), 143.7 (d, ${ }^{2} J(\mathrm{C}, \mathrm{P})=28.3 \mathrm{~Hz}$; qC-10), $141.3\left(\mathrm{~d},{ }^{3} J(\mathrm{C}, \mathrm{P})=2.0 \mathrm{~Hz}\right.$; $\left.\mathrm{qC}-o-\mathrm{CH}_{3}\right), 140.3\left(\mathrm{~d},{ }^{4} J(\mathrm{C}, \mathrm{P})=4.4 \mathrm{~Hz} ; \mathrm{C}-8\right), 140.0\left(\mathrm{~d},{ }^{3} J(\mathrm{C}, \mathrm{P})=11.2 \mathrm{~Hz} ; \mathrm{qC}-5\right), 138.6(\mathrm{~s}$; qC-ipso-Mes), $138.3\left(\mathrm{~d},{ }^{3} J(\mathrm{C}, \mathrm{P})=2.2 \mathrm{~Hz}\right.$; qC-o-Mes) $137.0\left(\mathrm{~d},{ }^{3} J(\mathrm{C}, \mathrm{P})=6.7 \mathrm{~Hz}\right.$; qC-9), $132.9\left(\mathrm{~d},{ }^{2} J(\mathrm{C}, \mathrm{P})=3.6 \mathrm{~Hz} ; \mathrm{C}-2\right) 129.9(\mathrm{~s} ; m-\mathrm{CH}), 128.5(\mathrm{~s} ; m-\mathrm{CH}), 123.7\left(\mathrm{~d},{ }^{1} J(\mathrm{C}, \mathrm{P})=20.3\right.$ $\mathrm{Hz}$; qC-1), 122.0 (s; C-7), 119.2 (d, ${ }^{3} J(\mathrm{C}, \mathrm{P})=5.0 \mathrm{~Hz}$; C-3), 30.8 (s; C-11/12), 30.1 (s; C11/12), $25.7\left(\mathrm{~s} ; o-\mathrm{CH}_{3}\right), 25.5\left(\mathrm{~s} ; p-\mathrm{CH}_{3}\right), 25.4\left(\mathrm{~d},{ }^{1} J(\mathrm{C}, \mathrm{P})=9.3 \mathrm{~Hz} ; 1 \times \mathrm{CH}\right), 25.3\left(\mathrm{~d},{ }^{1} J(\mathrm{C}, \mathrm{P})\right.$ $=18.4 \mathrm{~Hz} ; 1 \times \mathrm{CH}), 20.9\left(\mathrm{~s} ; o-\mathrm{CH}_{3}\right), 19.4\left(\mathrm{~d},{ }^{2} J(\mathrm{C}, \mathrm{P})=5.0 \mathrm{~Hz} ; 1 \times \mathrm{CH}_{3}\right), 18.1\left(\mathrm{~s} ; 1 \times \mathrm{CH}_{3}\right)$, $17.5\left(\mathrm{~d},{ }^{2} J(\mathrm{C}, \mathrm{P})=5.9 \mathrm{~Hz} ; 1 \times \mathrm{CH}_{3}\right), 17.2\left(\mathrm{~s} ; 1 \times \mathrm{CH}_{3}\right) ;{ }^{31} \mathbf{P}\left\{{ }^{1} \mathbf{H}\right\} \mathbf{N M R}\left(202.5 \mathrm{MHz}, \mathrm{CDCl}_{3}\right)$ $\delta=-3.6(\mathrm{~s})$; IR $\left(\mathrm{KBr} \operatorname{disc}, \mathrm{cm}^{-1}\right) v=2956 \mathrm{~s}\left(v_{\mathrm{C}-\mathrm{H}}\right), 2870 \mathrm{~m}, 1910 \mathrm{~m}, 1594 \mathrm{~s}, 1442 \mathrm{~s}, 1352 \mathrm{~m}$, $1238 \mathrm{~m}, 1160 \mathrm{~m}, 1035 \mathrm{~m}, 847 \mathrm{vs}, 716 \mathrm{~m}, 629 \mathrm{~m}, 604 \mathrm{~m}, 581 \mathrm{~m}, 542 \mathrm{~m}, 451 \mathrm{~m}$; Raman (glass capillary, $\left.\mathrm{cm}^{-1}\right) v=3058 \mathrm{~m}, 2930 \mathrm{vs}, 1596 \mathrm{~s}, 1574 \mathrm{~m}, 1441 \mathrm{~s}, 1415 \mathrm{~m}, 1354 \mathrm{~s}, 1341 \mathrm{~s}, 1294 \mathrm{~m}$, $1112 \mathrm{~m}, 956 \mathrm{~m}, 880 \mathrm{~m}, 822 \mathrm{~m}, 718 \mathrm{~m}, 858 \mathrm{vs}, 555 \mathrm{~s}, 385 \mathrm{~m}, 232 \mathrm{~m}, 219 \mathrm{~s}$; HRMS (APCI+): $\mathrm{m} / \mathrm{z}$ (\%) Calcd. for $\mathrm{C}_{27} \mathrm{H}_{34} \mathrm{ClPSb}$ : 545.1119, found 545.1122 (100) [M+H]; Calcd. for $\mathrm{C}_{27} \mathrm{H}_{33} \mathrm{PSb}$ : 509.1353, found 509.1358 (70) [M-Cl]; Elemental Analysis: Calcd. (\%) for $\mathrm{C}_{27} \mathrm{H}_{33} \mathrm{PClSb}$ (545.74): C 59.42, H 6.09; Found: C 59.31, H 6.12.

$i \operatorname{Pr}_{2} \mathbf{P}-\mathbf{A c e}-\mathrm{SbPh}_{2}$ (4): To a cooled $\left(-78^{\circ} \mathrm{C}\right)$ rapidly stirring solution of $\mathbf{1}(1.50 \mathrm{~g}, 4.3 \mathrm{mmol})$ in tetrahydrofuran $(40 \mathrm{~mL}), n$-butyllithium $(1.7 \mathrm{~mL}, 2.5 \mathrm{M}$ in hexane, $4.3 \mathrm{mmol})$ was added dropwise over $1 \mathrm{~h}$. The solution was maintained at $-78^{\circ} \mathrm{C}$ for a further $2 \mathrm{~h}$. A solution of chlorodiphenylstibine $(1.34 \mathrm{~g}, 4.3 \mathrm{mmol})$ in tetrahydrofuran (minimal) was added dropwise over a $1 \mathrm{~h}$ period whilst maintaining the reaction at $-78{ }^{\circ} \mathrm{C}$. The solution was left to warm to 
room temperature overnight. The volatiles were removed in vacuo and replaced with diethyl ether $(50 \mathrm{~mL})$ and washed with degassed water $(15 \mathrm{~mL})$. The organic layer was dried over magnesium sulfate and filtered. The volatiles were removed in vacuo to give a yellow powder $(1.94 \mathrm{~g}, 83 \%)$. Crystals suitable for X-ray diffraction were grown from acetonitrile at ambient conditions. ${ }^{1} \mathbf{H}$ NMR $\left(500.1 \mathrm{MHz}, \mathrm{CDCl}_{3}\right) \delta=7.66\left(\mathrm{dd},{ }^{3} J(\mathrm{H}, \mathrm{H})=7.1,{ }^{3} J(\mathrm{H}, \mathrm{P})=3.8 \mathrm{~Hz}, 1 \mathrm{H}\right.$; $\mathrm{H}-2), 7.59\left(\mathrm{~d},{ }^{3} J(\mathrm{H}, \mathrm{H})=7.0 \mathrm{~Hz}, 1 \mathrm{H} ; \mathrm{H}-8\right), 7.52-7.48(\mathrm{~m}, 4 \mathrm{H} ; o-\mathrm{H}), 7.37\left(\mathrm{~d},{ }^{3} J(\mathrm{H}, \mathrm{H})=7.1\right.$ $\mathrm{Hz}, 1 \mathrm{H} ; \mathrm{H}-3), 7.29-7.25$ (m, 6H; $m-\mathrm{H}, p-\mathrm{H}), 7.17\left(\mathrm{~d},{ }^{3} J(\mathrm{H}, \mathrm{H})=7.0 \mathrm{~Hz}, 1 \mathrm{H} ; \mathrm{H}-7\right), 3.48-3.39$ $(\mathrm{m}, 4 \mathrm{H}, \mathrm{H}-11,12), 2.12\left(\mathrm{dh},{ }^{3} J(\mathrm{H}, \mathrm{H})=7.0,{ }^{2} J(\mathrm{H}, \mathrm{P})=4.5 \mathrm{~Hz}, 2 \mathrm{H} ; \mathrm{CH}\right), 1.08\left(\mathrm{dd},{ }^{3} J(\mathrm{H}, \mathrm{P})=\right.$ $\left.15.0,{ }^{3} J(\mathrm{H}, \mathrm{H})=6.9 \mathrm{~Hz}, 6 \mathrm{H} ; 2 \times \mathrm{CH}_{3}\right), 0.62\left(\mathrm{dd},{ }^{3} J(\mathrm{H}, \mathrm{P})=12.1,{ }^{3} J(\mathrm{H}, \mathrm{H})=7.0 \mathrm{~Hz}, 6 \mathrm{H} ; 2 \times\right.$ $\left.\mathrm{CH}_{3}\right) ;{ }^{13} \mathbf{C}\left\{{ }^{1} \mathbf{H}\right\}$ NMR (125.8 MHz, $\left.\mathrm{CDCl}_{3}\right) \delta=149.0$ (s; qC-4), 147.5 (s; qC-6), 145.8 (d, ${ }^{5 \mathrm{ts}} J_{\mathrm{CP}}=40.3 \mathrm{~Hz}$; ipso), 142.1 (s; qC-9), 141.9 (s; qC-10), 140.1 (s; qC-5), 140.0 (s; C-8), $136.8(\mathrm{~s} ; o-\mathrm{C}), 134.1\left(\mathrm{~d},{ }^{2} J(\mathrm{C}, \mathrm{P})=2.5 \mathrm{~Hz} ; \mathrm{C}-2\right), 130.1\left(\mathrm{~d},{ }^{1} J(\mathrm{C}, \mathrm{P})=15.6 \mathrm{~Hz} ; \mathrm{qC}-1\right), 128.5(\mathrm{~s}$; $m$-C), 127.4 (s; p-C), 120.3 (s; C-7), 119.0 (s; C-3), 30.2 (s; C-11/12), 29.9 (s; C-11/12), 26.0 $\left(\mathrm{d},{ }^{1} J(\mathrm{C}, \mathrm{P})=13.1 \mathrm{~Hz} ; \mathrm{CH}\right), 20.1\left(\mathrm{~d},{ }^{2} J(\mathrm{C}, \mathrm{P})=16.6 \mathrm{~Hz} ; 2 \times \mathrm{CH}_{3}\right), 19.2\left(\mathrm{~d},{ }^{2} J(\mathrm{C}, \mathrm{P})=7.9 \mathrm{~Hz}\right.$; $\left.2 \times \mathrm{CH}_{3}\right) ;{ }^{31} \mathbf{P}\left\{{ }^{1} \mathbf{H}\right\} \mathbf{N M R}\left(202.5 \mathrm{MHz}, \mathrm{CDCl}_{3}\right) \delta=-21.9(\mathrm{~s}) . \mathbf{I R}\left(\mathrm{KBr} \operatorname{disc}, \mathrm{cm}^{-1}\right) v=3048 \mathrm{~m}$, $2923 \mathrm{~m}, 1600 \mathrm{~m}, 1430 \mathrm{~s}, 1326 \mathrm{~m}, 1249 \mathrm{~m}, 1065 \mathrm{~m}, 844 \mathrm{~s}, 731 \mathrm{vs}, 697 \mathrm{~s}, 653 \mathrm{~m}, 494 \mathrm{~m}, 456 \mathrm{~s}, 310 \mathrm{~m}$. Raman (glass capillary, $\mathrm{cm}^{-1}$ ) $v=3049 \mathrm{~s}, 2944 \mathrm{~m}, 2886 \mathrm{~m}, 1609 \mathrm{~s}, 1585 \mathrm{~m}, 1317 \mathrm{vs}, 1000 \mathrm{~s}$, 821m, 714m, 585m, 409m. HRMS (ES+): $m / z$ : Calcd. for $\mathrm{C}_{30} \mathrm{H}_{33} \mathrm{PSb}$ : 545.1355, found $545.1358[\mathrm{M}+\mathrm{H}]$; Calcd. for $\mathrm{C}_{24} \mathrm{H}_{27} \mathrm{PSb}$ : 467.0886, found 467.0883 [M-Ph]. Elemental Analysis: Calcd. (\%) for $\mathrm{C}_{30} \mathrm{H}_{32} \mathrm{PSb}$ (545.31): C 66.08, H 5.91; Found: C 66.13, H 5.85.

$i \operatorname{Pr}_{2} \mathbf{P}-A_{c e-S_{C C l}}$ (5): A suspension of $1(1.00 \mathrm{~g}, 2.2 \mathrm{mmol})$ in diethyl ether $(20 \mathrm{~mL})$ was cooled to $0{ }^{\circ} \mathrm{C}$. A solution of $\mathrm{SO}_{2} \mathrm{Cl}_{2}(0.30 \mathrm{~g}, 0.18 \mathrm{~mL}, 2.2 \mathrm{mmol})$ in diethyl ether $(5 \mathrm{~mL})$ was added dropwise. The solution was left to stir for $1 \mathrm{~h}$ at $0^{\circ} \mathrm{C}$ and $16 \mathrm{~h}$ at $\mathrm{RT}$. The volatiles were removed in vacuo to give a yellow solid (1.05 g, 99\%). Crystals suitable for X-ray diffraction were grown from toluene at $-35^{\circ} \mathrm{C}$. Once isolated, the compound decomposes at room temperature in 2-3 days. It decomposes instantly in chlorinated solvents, while it is stable in benzene solution for $c a .7$ days (at room temperature) and for $c a$. month at $-35^{\circ} \mathrm{C}$. For this reason, no further characterisation other than solution state NMR spectra could be acquired. Due to the very unstable nature of $\mathbf{5}$, neither mass spectrometry nor elemental analysis could be performed. ${ }^{1} \mathbf{H}$ NMR $\left(500.1 \mathrm{MHz}, \mathrm{C}_{6} \mathrm{D}_{6}\right) \delta=8.80\left(\mathrm{dd},{ }^{3} J(\mathrm{H}, \mathrm{H})=7.2,{ }^{3} J(\mathrm{H}, \mathrm{P})=3.3 \mathrm{~Hz}\right.$, $1 \mathrm{H}$; H-2), 7.12 (m, 1H; H-8), $6.90\left(\mathrm{~d},{ }^{3} J(\mathrm{H}, \mathrm{H})=6.8 \mathrm{~Hz}, 1 \mathrm{H} ; \mathrm{H}-7\right), 6.85\left(\mathrm{~d},{ }^{3} J(\mathrm{H}, \mathrm{H})=7.2 \mathrm{~Hz}\right.$, 1H; H-3), 2.84-2.74 (m, 2H; CH), 2.79-2.75 (m, 2H; H-12), $2.69-2.63$ (m, 2H; H-11), 1.28 
$\left(\mathrm{dd},{ }^{3} J(\mathrm{H}, \mathrm{P})=16.8,{ }^{3} J(\mathrm{H}, \mathrm{H})=6.7 \mathrm{~Hz}, 6 \mathrm{H} ; 2 \times \mathrm{CH}_{3}\right), 1.24\left(\mathrm{dd},{ }^{3} J(\mathrm{H}, \mathrm{P})=16.0,{ }^{3} J(\mathrm{H}, \mathrm{H})=6.7\right.$ $\left.\mathrm{Hz}, 6 \mathrm{H} ; 2 \times \mathrm{CH}_{3}\right) ;{ }^{13} \mathbf{C}\left\{{ }^{1} \mathbf{H}\right\}$ NMR (125.8 MHz, $\left.\mathrm{C}_{6} \mathrm{D}_{6}\right) \delta=154.0$ (s; qC-4), 153.0 (s; qC-6), 149.6 (s; qC-9), 138.9 (d, $\left.{ }^{3} J(\mathrm{C}, \mathrm{P})=7.5 \mathrm{~Hz} ; \mathrm{qC}-5\right), 134.5$ (s; C-8), 129.1 (d, ${ }^{3} J(\mathrm{C}, \mathrm{P})=9.4 \mathrm{~Hz}$; qC-10), $128.9\left(\mathrm{~d},{ }^{3} J(\mathrm{C}, \mathrm{P})=8.1 \mathrm{~Hz} ; \mathrm{C}-2\right), 120.6\left(\mathrm{~d},{ }^{3} J(\mathrm{C}, \mathrm{P})=6.6 \mathrm{~Hz} ; \mathrm{C}-3\right), 119.2\left(\mathrm{~d},{ }^{4} J(\mathrm{C}, \mathrm{P})\right.$ $=7.8 \mathrm{~Hz} ; \mathrm{C}-7), 112.6\left(\mathrm{~d},{ }^{1} J(\mathrm{C}, \mathrm{P})=42.6 \mathrm{~Hz} ; \mathrm{qC}-1\right), 30.7$ (s; C-12), 29.6 (s; C-11), 26.3 (d, ${ }^{1} J$ $(\mathrm{C}, \mathrm{P})=18.2 \mathrm{~Hz} ; \mathrm{CH}), 19.1\left(\mathrm{~s} ; 2 \times \mathrm{CH}_{3}\right), 18.5\left(\mathrm{~d},{ }^{2} J(\mathrm{C}, \mathrm{P})=3.0 \mathrm{~Hz} ; 2 \times \mathrm{CH}_{3}\right) ;{ }^{31} \mathbf{P}\left\{{ }^{1} \mathbf{H}\right\} \mathbf{N M R}$ $\left(202.5 \mathrm{MHz}, \mathrm{C}_{6} \mathrm{D}_{6}\right) \delta=-20.1$ (s).

iPr $\mathbf{P r}_{2} \mathbf{P}-\mathbf{A c e}-\mathrm{SbPhCl}_{3}(6)$ : To a cooled $\left({ }^{\circ}{ }^{\circ} \mathrm{C}\right)$ rapidly stirring suspension of 3 (1.00 g, 1.99 $\mathrm{mmol})$ in hexane $(20 \mathrm{~mL})$ a solution of sulfuryl chloride $(335 \mathrm{mg}, 0.2 \mathrm{~mL}, 2.4 \mathrm{mmol})$ in hexane $(6 \mathrm{~mL})$ was added drop wise over $15 \mathrm{~min}$. The solution was left to stir at $0{ }^{\circ} \mathrm{C}$ for a further $30 \mathrm{~min}$ before being left to stir at room temperature for a further $30 \mathrm{~min}$. The volatiles were removed in vacuo to give a white powder (1.10 g, 97\%) (M. p. decomp. above $197{ }^{\circ} \mathrm{C}$ with no melting). Crystals were grown from acetonitrile at room temperature. ${ }^{1} \mathbf{H}$ NMR $\left(500.1 \mathrm{MHz}, \mathrm{CD}_{2} \mathrm{Cl}_{2}\right) \delta=8.82\left(\mathrm{dd},{ }^{3} J(\mathrm{H}, \mathrm{H})=7.4,{ }^{4} J(\mathrm{H}, \mathrm{P})=2.3 \mathrm{~Hz}, 1 \mathrm{H} ; \mathrm{H}-8\right), 8.65-8.58(\mathrm{~m}$, $2 \mathrm{H} ; o-\mathrm{H}), 7.88\left(\mathrm{dd},{ }^{3} J(\mathrm{H}, \mathrm{H})=7.4,{ }^{3} J(\mathrm{H}, \mathrm{P})=7.4 \mathrm{~Hz}, 1 \mathrm{H} ; \mathrm{H}-2\right)$, 7.64-7.53 (m, 5H; H-3, 7, m$\mathrm{H}, p-\mathrm{H}), 3.60-3.51(\mathrm{~m}, 4 \mathrm{H} ; \mathrm{H}-11,12), 3.01\left(\mathrm{dh},{ }^{2} J(\mathrm{H}, \mathrm{P})=11.8,{ }^{3} J(\mathrm{H}, \mathrm{H})=7.1 \mathrm{~Hz}, 2 \mathrm{H} ; \mathrm{CH}\right)$, $1.33\left(\mathrm{dd},{ }^{3} J(\mathrm{H}, \mathrm{P})=16.2,{ }^{3} J(\mathrm{H}, \mathrm{H})=7.0 \mathrm{~Hz}, 6 \mathrm{H} ; 2 \times \mathrm{CH}_{3}\right), 1.19\left(\mathrm{dd},{ }^{3} J(\mathrm{H}, \mathrm{P})=17.0,{ }^{3} J(\mathrm{H}, \mathrm{H})\right.$ $\left.=7.2 \mathrm{~Hz}, 6 \mathrm{H} ; 2 \times \mathrm{CH}_{3}\right) ;{ }^{13} \mathbf{C}$ NMR $\left(125.8 \mathrm{MHz}, \mathrm{CD}_{2} \mathrm{Cl}_{2}\right) \delta=162.6\left(\mathrm{~d},{ }^{2} J(\mathrm{C}, \mathrm{P})=52.3 \mathrm{~Hz}\right.$; ipsoPh), 153.4 (s; qC-6), 152.9 (s; qC-4), 150.0 (s; qC-9), $139.8\left(\mathrm{~d},{ }^{3} J(\mathrm{C}, \mathrm{P})=7.1 \mathrm{~Hz} ; \mathrm{qC}-5\right)$, 134.6 (s; C-2), 130.7 (s; qC-10), 130.6 (s; m-C), 129.9 (s; o-C), 129.2 (s; p-C), 128.9 (d, ${ }^{3} J$ $(\mathrm{C}, \mathrm{P})=8.0 \mathrm{~Hz} ; \mathrm{C}-8), 120.8\left(\mathrm{~d},{ }^{5} J(\mathrm{C}, \mathrm{P})=5.8 \mathrm{~Hz}\right.$; C-7), $120.1\left(\mathrm{~d},{ }^{3} J(\mathrm{C}, \mathrm{P})=6.9 \mathrm{~Hz}\right.$; C-3), $114.9\left(\mathrm{~d},{ }^{1} J(\mathrm{C}, \mathrm{P})=37.8 \mathrm{~Hz}\right.$; C-1), 31.2 (s; C-11), 30.2 (s; C-12), $26.7\left(\mathrm{~d},{ }^{1} J(\mathrm{C}, \mathrm{P})=15.0 \mathrm{~Hz}\right.$; $\mathrm{CH}), 19.1\left(\mathrm{~s} ; 2 \times \mathrm{CH}_{3}\right), 18.7\left(\mathrm{~s} ; 2 \times \mathrm{CH}_{3}\right) ;{ }^{31} \mathbf{P}\left\{{ }^{1} \mathbf{H}\right\} \mathbf{N M R}\left(202.5 \mathrm{MHz}, \mathrm{CD}_{2} \mathrm{Cl}_{2}\right) \delta=-28.4(\mathrm{~s})$; IR $\left(\mathrm{KBr} \operatorname{disc}, \mathrm{cm}^{-1}\right) v=3051 \mathrm{~m}\left(v_{\mathrm{Ar}-\mathrm{H}}\right), 2930 \mathrm{~m}\left(v_{\mathrm{C}-\mathrm{H}}\right), 1638 \mathrm{~s}, 1595 \mathrm{~s}, 1472 \mathrm{~m}, 1443 \mathrm{~m}, 1357 \mathrm{~s}$, $1259 \mathrm{~m}, 1183 \mathrm{~m}, 1057 \mathrm{~m}, 994 \mathrm{~m}, 848 \mathrm{~s}, 739 \mathrm{~s}, 683 \mathrm{~m}, 600 \mathrm{~m}, 459 \mathrm{~s}, 275 \mathrm{~s}$; MS (ES+): m/z (\%) 575.55 (100) $[\mathrm{M}+\mathrm{H}]$; Elemental Analysis Calcd. (\%) for $\mathrm{C}_{24} \mathrm{H}_{27} \mathrm{Cl}_{3} \mathrm{PSb}\left(574.56 \mathrm{~g} \mathrm{~mol}^{-1}\right.$ ): C 50.35, H 4.76; Found: C 50.17, H 4.71.

$i \operatorname{Pr}_{2} \mathbf{P}-A c e-\mathrm{SbPh}_{2} \mathbf{C l}_{2}$ (7): To a cooled $\left(-78^{\circ} \mathrm{C}\right)$, rapidly stirring solution of $\mathbf{1}(1.00 \mathrm{~g}, 2.9$ $\mathrm{mmol})$ in diethyl ether $(20 \mathrm{~mL}), n$-butyllithium $(1.15 \mathrm{~mL}$ of $2.5 \mathrm{M}$ solution in hexanes, 2.9 mmol) was added over a period of $1 \mathrm{~h}$. The solution was left to stir at this temperature for a further $2 \mathrm{~h}$. The resulting suspension was then added in small batches via cannula to a 
solution of diphenylantimony trichloride dimer $(1.10 \mathrm{~g}, 1.45 \mathrm{mmol})$ in diethyl ether $(30 \mathrm{~mL})$ at $-40^{\circ} \mathrm{C}$ over a $2 \mathrm{~h}$ period. The reaction mixture was left to warm up to room temperature with rapid stirring overnight. The solid was collected from the white suspension by filtration and was washed with degassed water $(15 \mathrm{~mL})$. After drying in vacuo 7 was obtained as a white powder (1.25 g, 70\%) (M. p. $132^{\circ} \mathrm{C}$ with decomposition). Crystals suitable for X-ray diffraction were grown from acetonitrile at $0^{\circ} \mathrm{C}$.

${ }^{1}$ H NMR $\left(500.1 \mathrm{MHz}, \mathrm{CDCl}_{3}\right) \delta=8.39\left(\mathrm{~d},{ }^{3} J(\mathrm{H}, \mathrm{H})=8.4 \mathrm{~Hz}, 2 \mathrm{H} ; o\right.$-H-trans $), 8.23\left(\mathrm{dd},{ }^{3} J\right.$ $\left.(\mathrm{H}, \mathrm{H})=6.6,{ }^{4} J(\mathrm{H}, \mathrm{H})=2.9 \mathrm{~Hz}, 2 \mathrm{H} ; o-\mathrm{H}-c i s B\right), 7.79\left(\mathrm{dd},{ }^{3} J(\mathrm{H}, \mathrm{H})=7.1,{ }^{5} J(\mathrm{H}, \mathrm{P})=5.3 \mathrm{~Hz}\right.$, $1 \mathrm{H} ; \mathrm{H}-8), 7.71\left(\mathrm{dd},{ }^{3} J(\mathrm{H}, \mathrm{H})=7.3,{ }^{3} J(\mathrm{H}, \mathrm{P})=2.9 \mathrm{~Hz}, 1 \mathrm{H} ; \mathrm{H}-2\right), 7.52-7.40(\mathrm{~m}, 7 \mathrm{H} ; \mathrm{H}-7, m-\mathrm{H}$ $\times 2, p-\mathrm{H} \times 2), 7.25\left(\mathrm{dd},{ }^{3} J(\mathrm{H}, \mathrm{H})=7.2,{ }^{4} J(\mathrm{H}, \mathrm{P})=1.6 \mathrm{~Hz}, 1 \mathrm{H} ; \mathrm{H}-3\right), 3.49-3.40(\mathrm{~m}, 4 \mathrm{H} ; \mathrm{H}-$ 11,12), $2.51\left(\mathrm{dh},{ }^{2} J(\mathrm{H}, \mathrm{P})=10.5,{ }^{3} J(\mathrm{H}, \mathrm{H})=7.1 \mathrm{~Hz}, 2 \mathrm{H}\right.$; H-13), $1.13\left(\mathrm{dd},{ }^{3} J(\mathrm{H}, \mathrm{P})=14.6,{ }^{3} J\right.$ $\left.(\mathrm{H}, \mathrm{H})=7.0 \mathrm{~Hz}, 6 \mathrm{H} ; \mathrm{H}-14,2 \times \mathrm{CH}_{3}\right), 1.06\left(\mathrm{dd},{ }^{3} J(\mathrm{H}, \mathrm{P})=14.4,{ }^{3} J(\mathrm{H}, \mathrm{H})=7.1 \mathrm{~Hz}, 6 \mathrm{H} ; \mathrm{H}-14\right.$, $\left.2 \times \mathrm{CH}_{3}\right) ;{ }^{13} \mathbf{C}\left\{{ }^{1} \mathbf{H}\right\} \mathbf{N M R}\left(125.8 \mathrm{MHz}, \mathrm{CDCl}_{3}\right) \delta=161.5\left(\mathrm{~d},{ }^{5 \text { ts }} J(\mathrm{C}, \mathrm{P})=77.8 \mathrm{~Hz} ;\right.$ ipso-cisB $)$, 149.8 (s; qC-6), 149.1 (s; qC-4), $148.3\left(\mathrm{~d},{ }^{3} J(\mathrm{C}, \mathrm{P})=86.4 \mathrm{~Hz}\right.$; ipso-trans $), 140.9\left(\mathrm{~d},{ }^{1} J(\mathrm{C}, \mathrm{P})=\right.$ $14.8 \mathrm{~Hz} ; \mathrm{qC}-1), 140.0\left(\mathrm{~d},{ }^{3} J(\mathrm{C}, \mathrm{P})=6.2 \mathrm{~Hz} ; \mathrm{qC}-5\right), 136.2(\mathrm{~s} ; o-\mathrm{C}), 132.9\left(\mathrm{~d},{ }^{2} J(\mathrm{C}, \mathrm{P})=3.8 \mathrm{~Hz}\right.$; $\mathrm{C}-8), 132.5\left(\mathrm{~d},{ }^{2} J(\mathrm{C}, \mathrm{P})=15.4 \mathrm{~Hz} ; \mathrm{qC}-10\right), 131.6(\mathrm{~s} ; o-\mathrm{C}), 129.9$ (s; C-2), 129.8 (s; $\left.m-\mathrm{C}\right)$, $129.6(\mathrm{~s} ; m-\mathrm{C}), 128.8(\mathrm{~s} ; p-\mathrm{C}), 128.5(\mathrm{~s} ; p-\mathrm{C}), 122.0\left(\mathrm{~d},{ }^{3} J(\mathrm{C}, \mathrm{P})=10.6 \mathrm{~Hz} ; \mathrm{qC}-9\right), 119.9$ (d, ${ }^{5}$ $(\mathrm{C}, \mathrm{P})=3.1 \mathrm{~Hz} ; \mathrm{C}-7), 119.7\left(\mathrm{~d},{ }^{3} J(\mathrm{C}, \mathrm{P})=6.3 \mathrm{~Hz}\right.$; C-3), 30.7 (s; C-12), 30.1 (s; C-11), 26.8 (s; $\mathrm{CH}), 19.6\left(\mathrm{~d},{ }^{2} J(\mathrm{C}, \mathrm{P})=4.5 \mathrm{~Hz} ; 2 \times \mathrm{CH}_{3}\right), 19.1\left(\mathrm{~d},{ }^{2} J(\mathrm{C}, \mathrm{P})=6.9 \mathrm{~Hz} ; 2 \times \mathrm{CH}_{3}\right) ;{ }^{31} \mathbf{P}\left\{{ }^{1} \mathbf{H}\right\} \mathbf{~ N M R}$ $\left(202.5 \mathrm{MHz}, \mathrm{CDCl}_{3}\right) \delta=-45.6(\mathrm{~s})$; IR $\left(\mathrm{KBr}\right.$ disc, $\left.\mathrm{cm}^{-1}\right) v=2927 \mathrm{~m}\left(v_{\mathrm{Ar}-\mathrm{H}}\right), 2364 \mathrm{~m}, 1639 \mathrm{~s}$, 1476m, 1434s, 1330m, 1256m, 1063m, 996m, 849m, 735s, 686s, 460s, 278s, 247s; Raman (glass capillary, $\left.\mathrm{cm}^{-1}\right) v=3054 \mathrm{~s}\left(v_{\mathrm{Ar}-\mathrm{H}}\right), 2932 \mathrm{~s}\left(v_{\mathrm{C}-\mathrm{H}}\right), 1597 \mathrm{~m}, 1570 \mathrm{~m}, 1412 \mathrm{~m}, 1352 \mathrm{~s}$, $1159 \mathrm{w}, 1021 \mathrm{~m}, 999 \mathrm{vs}, 819 \mathrm{~m}, 655 \mathrm{~s}, 583 \mathrm{~s}, 553 \mathrm{~m}, 472 \mathrm{w}, 278 \mathrm{vs}\left(\mathrm{v}_{\mathrm{Sb}-\mathrm{Cl}}\right), 260 \mathrm{vs}$ and $204 \mathrm{~m}$; MS (ES+): $m / z$ (\%) 575.15 (100) $[\mathrm{M}-2 \times \mathrm{Cl}+\mathrm{OMe}]$; HRMS (ES+): $m / z$ : Calcd. for $\mathrm{C}_{31} \mathrm{H}_{35} \mathrm{PSbO}$ : 575.1464, found 575.1452; Elemental Analysis Calcd. (\%) for $\mathrm{C}_{30} \mathrm{H}_{32} \mathrm{Cl}_{2} \mathrm{PSb}$ $\left(616.21 \mathrm{~g} \mathrm{~mol}^{-1}\right)$ : C 58.47, H 5.23; Found: C 58.56, H 5.31.

$i \operatorname{Pr}_{2} \mathbf{P}-\mathrm{Ace}-\mathrm{SbPh}_{3} \mathrm{Cl}(\mathbf{8})$ : To a cooled $\left(-78^{\circ} \mathrm{C}\right)$, rapidly stirring solution of $\mathbf{1}$ (4.12 g, 11.80 $\mathrm{mmol})$ in diethyl ether $(120 \mathrm{~mL}), n$-butyllithium $(4.70 \mathrm{~mL}$ of $2.5 \mathrm{M}$ solution in hexanes, $11.80 \mathrm{mmol}$ ) was added over a period of $1 \mathrm{~h}$ and the mixture was left to stir for $2 \mathrm{~h}$ at the same temperature. The resulting suspension was the added in small batches via cannula to a rapidly stirring solution of triphenylantimony dichloride $(5.00 \mathrm{~g}, 11.80 \mathrm{mmol})$ in diethyl ether $(100 \mathrm{~mL})$ at $-40^{\circ} \mathrm{C}$ over a period of $2 \mathrm{~h}$. The reaction mixture was left to stir and warm up to room temperature with rapid stirring overnight. The solid was collected from the pale yellow 
suspension by filtration and washed with degassed water $(25 \mathrm{~mL})$. After drying in vacuo pure 8 was obtained as a white powder (6.91 g, 89\%) (M. p. $168^{\circ} \mathrm{C}$ with decomposition). Crystals suitable for X-ray diffraction were obtained from acetonitrile at $0^{\circ} \mathrm{C} .{ }^{1} \mathbf{H}$ NMR $(400.1 \mathrm{MHz}$, $\left.\mathrm{CDCl}_{3}\right) \delta=7.81-7.76(\mathrm{~m}, 6 \mathrm{H} ; o-\mathrm{H}), 7.77-7.75\left(\mathrm{~m} \sim \mathrm{d},{ }^{3} J(\mathrm{H}, \mathrm{H})=7.2 \mathrm{~Hz}, 1 \mathrm{H} ; \mathrm{H}-8\right), 7.69(\mathrm{dd}$, $\left.{ }^{3} J(\mathrm{H}, \mathrm{H})=7.3,{ }^{3} J(\mathrm{H}, \mathrm{P})=1.3 \mathrm{~Hz}, 1 \mathrm{H} ; \mathrm{H}-2\right), 7.49\left(\mathrm{~d},{ }^{3} J(\mathrm{H}, \mathrm{H})=7.2 \mathrm{~Hz}, 1 \mathrm{H} ; \mathrm{H}-7\right), 7.45-7.37$ $(\mathrm{m}, 9 \mathrm{H} ; m-\mathrm{H}, p-\mathrm{H}), 7.30\left(\mathrm{~d},{ }^{3} J(\mathrm{H}, \mathrm{H})=7.3 \mathrm{~Hz}, 1 \mathrm{H} ; \mathrm{H}-3\right), 3.53-3.43(\mathrm{~m}, 4 \mathrm{H} ; \mathrm{H}-11,12), 2.27$ $\left(\mathrm{dh},{ }^{2} J(\mathrm{H}, \mathrm{P})=9.2,{ }^{3} J(\mathrm{H}, \mathrm{H})=7.1 \mathrm{~Hz}, 2 \mathrm{H} ; \mathrm{H}-13\right), 1.00\left(\mathrm{dd},{ }^{3} J(\mathrm{H}, \mathrm{P})=14.0,{ }^{3} J(\mathrm{H}, \mathrm{H})=7.0 \mathrm{~Hz}\right.$, $\left.6 \mathrm{H} ; 2 \times \mathrm{CH}_{3}\right), 0.56\left(\mathrm{dd},{ }^{3} J(\mathrm{H}, \mathrm{P})=14.6,{ }^{3} \mathrm{~J}(\mathrm{H}, \mathrm{H})=7.2 \mathrm{~Hz}, 6 \mathrm{H} ; 2 \times \mathrm{CH}_{3}\right) ;{ }^{13} \mathbf{C}\left\{{ }^{1} \mathbf{H}\right\} \mathbf{~ N M R}$ $\left(100.6 \mathrm{MHz}, \mathrm{CDCl}_{3}\right) \delta=150.6(\mathrm{~s} ; \mathrm{qC}-4), 150.2$ (s; qC-6), $140.6\left(\mathrm{~d},{ }^{5 \text { ts }} J(\mathrm{C}, \mathrm{P})=32.6 \mathrm{~Hz}\right.$; qCipso), $140.3\left(\mathrm{~d},{ }^{3} J(\mathrm{C}, \mathrm{P})=6.4 \mathrm{~Hz}\right.$; qC-5), $136.0\left(\mathrm{~d},{ }^{2} J(\mathrm{C}, \mathrm{P})=18.8 \mathrm{~Hz}\right.$; qC-10), 135.4 (s; o-C), 135.1 (br s; C-2), 133.6 (d, ${ }^{4} J(\mathrm{C}, \mathrm{P})=2.9 \mathrm{~Hz}$; C-8), 132.8 (br s; qC-1), 130.3 (s; $p$-C), 129.2 $(\mathrm{s} ; m-\mathrm{C}), 123.0\left(\mathrm{~d},{ }^{3} J(\mathrm{C}, \mathrm{P})=6.4 \mathrm{~Hz} ; \mathrm{qC}-9\right), 120.5\left(\mathrm{~d},{ }^{3} J(\mathrm{C}, \mathrm{P})=4.1 \mathrm{~Hz} ; \mathrm{C}-3\right), 120.3\left(\mathrm{~d},{ }^{5} J\right.$ $(\mathrm{C}, \mathrm{P})=2.0 \mathrm{~Hz}$; C-7), 30.6 (s; C-11/12), 30.4 (s; C-11/12), 25.9 (br s; C-13), 19.1 (d, ${ }^{2} J(\mathrm{C}, \mathrm{P})$ $\left.=6.1 \mathrm{~Hz} ; 2 \times \mathrm{CH}_{3}\right), 18.8\left(\mathrm{~d},{ }^{2} J(\mathrm{C}, \mathrm{P})=6.7 \mathrm{~Hz}, 2 \times \mathrm{CH}_{3}\right) ;{ }^{31} \mathbf{P}\left\{{ }^{1} \mathbf{H}\right\} \mathbf{N M R}\left(162.0 \mathrm{MHz}, \mathrm{CDCl}_{3}\right)$ $\delta=-41.6(\mathrm{~s})$; IR $\left(\mathrm{KBr}\right.$ disc, $\left.\mathrm{cm}^{-1}\right) v=3050 \mathrm{~m}\left(v_{\mathrm{Ar}-\mathrm{H}}\right), 2952 \mathrm{~m}\left(v_{\mathrm{C}-\mathrm{H}}\right), 2364 \mathrm{w}, 1638 \mathrm{~s}, 1595 \mathrm{~s}$, 1476vs, 1429vs, 1340m, 1257m, 1063vs, 998m, 842s, 730vs, 691vs, 653m, 583m, 455s, $352 \mathrm{~m}, 245 \mathrm{~s}\left(v_{\mathrm{Sb}-\mathrm{Cl}}\right)$; Raman (glass capillary, $\left.\mathrm{cm}^{-1}\right) v=3052 \mathrm{~s}\left(v_{\mathrm{Ar}-\mathrm{H}}\right), 2951 \mathrm{~s}\left(v_{\mathrm{C}-\mathrm{H}}\right), 2920 \mathrm{~m}$, $2888 \mathrm{~m}, 1603 \mathrm{~m}, 1570 \mathrm{~s}, 1452 \mathrm{~m}, 1350 \mathrm{~s}, 1342 \mathrm{~s}, 1022 \mathrm{~s}, 1001 \mathrm{vs}, 618 \mathrm{~m}, 585 \mathrm{~s}, 554 \mathrm{~m}, 254 \mathrm{~s}\left(v_{\mathrm{Sb}-}\right.$ $\mathrm{Cl}), 232 \mathrm{~s}, 216 \mathrm{~s}$, and 198m; MS (ES+): m/z (\%) 621.07 (100) [M-Cl]; HRMS (ES+): m/z: Calcd. for $\mathrm{C}_{36} \mathrm{H}_{37} \mathrm{PSb}$ : 621.1671, found 621.1652; Elemental Analysis Calcd. (\%) for $\mathrm{C}_{36} \mathrm{H}_{37} \mathrm{PSbCl}$ (657.87 $\left.\mathrm{g} \mathrm{mol}^{-1}\right)$ : C 65.73, H 5.67; Found: C 65.64, H 5.59.

$i \operatorname{Pr}_{2} \mathbf{P}-A c e-S_{3 b} \mathbf{P h}_{4}(9)$ : To a cooled $\left(-78^{\circ} \mathrm{C}\right)$ rapidly stirring solution of $\mathbf{1}(1.40 \mathrm{~g}, 4.0 \mathrm{mmol})$ in diethyl ether $(30 \mathrm{~mL}), n$-butyllithium $(1.60 \mathrm{~mL}, 2.5 \mathrm{M}$ in hexane, $4.0 \mathrm{mmol})$ was added drop wise over a $1 \mathrm{~h}$ period. The solution was left to stir at $-78^{\circ} \mathrm{C}$ for a further $2 \mathrm{~h}$.

After this time the solution was added to a cooled $\left(-10^{\circ} \mathrm{C}\right)$ solution of bromotetraphenylstiborane $(2.00 \mathrm{~g}, 4.0 \mathrm{mmol})$ in diethyl ether $(30 \mathrm{~mL})$ over a $1 \mathrm{~h}$ period. The solution was left to stir and warm to room temperature overnight. The white solid was collected via filtration and washed with diethyl ether $(20 \mathrm{~mL})$ and degassed water $(20 \mathrm{~mL})$ to give a white powder (2.31 g, 84\%) (M. p. decomp. above $180^{\circ} \mathrm{C}$ with no melting). Crystals suitable for X-ray diffraction were grown from chloroform at room temperature.

${ }^{1}$ H NMR $\left(500.1 \mathrm{MHz} \mathrm{CDCl}_{3}\right) \delta=7.85-7.79(\mathrm{~m}, 2 \mathrm{H} ; m-\mathrm{H}-c i s B /$ trans $), 7.58\left(\mathrm{dd},{ }^{3} J(\mathrm{H}, \mathrm{H})=\right.$ $\left.7.1 \mathrm{~Hz},{ }^{3} J(\mathrm{H}, \mathrm{P})=4.9 \mathrm{~Hz}, 1 \mathrm{H} ; \mathrm{H}-2\right), 7.55-7.51(\mathrm{~m}, 1 \mathrm{H} ; \mathrm{H}-8), 7.51-7.47(\mathrm{~m}, 3 \mathrm{H} ; o-\mathrm{H}, p-\mathrm{H}-$ cisB/trans), 7.40-7.37 (m, 2H; m-H-cisB/trans), 7.36-7.34 (m, 1H; H-3), 7.31-7.22 (m, 3H; 
$o-\mathrm{H}, p-\mathrm{H}), 7.19\left(\mathrm{~d},{ }^{3} J(\mathrm{H}, \mathrm{H})=6.8 \mathrm{~Hz}, 1 \mathrm{H} ; \mathrm{H}-7\right), 7.10-7.03(\mathrm{~m}, 2 \mathrm{H} ; p-\mathrm{H}-c i s A), 6.98-6.91(\mathrm{~m}$, $8 \mathrm{H} ; p$-H-cisA), 3.49 (s, 4H; H-11,12), $1.99\left(\mathrm{dh},{ }^{2} J(\mathrm{H}, \mathrm{P})=9.0,{ }^{3} J(\mathrm{H}, \mathrm{H})=7.1 \mathrm{~Hz}, 2 \mathrm{H} ; \mathrm{H}-13\right)$, $1.14\left(\mathrm{dd},{ }^{3} J(\mathrm{H}, \mathrm{P})=13.0,{ }^{3} J(\mathrm{H}, \mathrm{H})=6.9 \mathrm{~Hz}, 6 \mathrm{H} ; 2 \times \mathrm{CH}_{3}\right), 0.21\left(\mathrm{dd},{ }^{3} J(\mathrm{H}, \mathrm{P})=14.0,{ }^{3} J(\mathrm{H}, \mathrm{H})\right.$ $\left.=7.2 \mathrm{~Hz}, 6 \mathrm{H} ; 2 \times \mathrm{CH}_{3}\right) ;{ }^{13} \mathbf{C}\left\{{ }^{1} \mathbf{H}\right\} \mathbf{~ N M R}\left(125.8 \mathrm{MHz}, \mathrm{CDCl}_{3}\right) \delta=158.7\left(\mathrm{~d},{ }^{5 \text { ts }} J(\mathrm{C}, \mathrm{P})=31.1\right.$ $\mathrm{Hz}$; ipso-cisB), 149.6 (s; qC-4), 148.7 (d, ${ }^{3} J(\mathrm{C}, \mathrm{P})=11.6 \mathrm{~Hz}$; qC-1), 146.2 (s; qC-6), 141.8 (s; qC-9), 141.6 (s; ipso-cis $A), 139.9$ (d, ${ }^{4} J(\mathrm{C}, \mathrm{P})=7.0 \mathrm{~Hz}$; qC-5), $139.4\left(\mathrm{~d},{ }^{5 \mathrm{ts}} J(\mathrm{C}, \mathrm{P})=35.7 \mathrm{~Hz}\right.$; ipso-trans), $138.5\left(\mathrm{~d},{ }^{2} J(\mathrm{C}, \mathrm{P})=21.8 \mathrm{~Hz}\right.$; qC-10), $137.0(\mathrm{~s} ; m$-C-cisB $), 136.3\left(\mathrm{~d},{ }^{6 \mathrm{ts}} J(\mathrm{C}, \mathrm{P})=\right.$ $2.5 \mathrm{~Hz}$; o-C-trans), 135.3 (s; m-C-trans), 134.8 (s; m-C-cisA), $132.7\left(\mathrm{~d},{ }^{2} J(\mathrm{C}, \mathrm{P})=3.2 \mathrm{~Hz}\right.$; C2), 131.0 (s; C-8), 129.5 (s; p-C-trans), 128.7 (s;o-C-cisB), 128.4 (s; p-C-cisB), 127.6 (s; oC-trans), $119.2(\mathrm{~s} ; \mathrm{C}-7), 119.0\left(\mathrm{~d} ;{ }^{3} J(\mathrm{C}, \mathrm{P})=2.9 \mathrm{~Hz} ; \mathrm{C}-3\right), 30.4(\mathrm{~s} ; \mathrm{C}-11), 30.0(\mathrm{~s} ; \mathrm{C}-12), 27.4$ $\left(\mathrm{d},{ }^{1} J(\mathrm{C}, \mathrm{P})=6.3 \mathrm{~Hz} ; \mathrm{C}-13\right), 19.5\left(\mathrm{~d},{ }^{2} J(\mathrm{C}, \mathrm{P})=8.2 \mathrm{~Hz} ; 2 \times \mathrm{CH}_{3}\right), 19.2\left(\mathrm{~d},{ }^{2} J(\mathrm{C}, \mathrm{P})=8.2 \mathrm{~Hz} ; 2\right.$ $\left.\times \mathrm{CH}_{3}\right) ;{ }^{31} \mathbf{P}\left\{{ }^{1} \mathbf{H}\right\}$ NMR $\left(202.5 \mathrm{MHz}, \mathrm{CDCl}_{3}\right) \delta=-33.8(\mathrm{~s}) ; \mathbf{I R}\left(\mathrm{KBr}\right.$ disc, $\left.\mathrm{cm}^{-1}\right) v=3046 \mathrm{~m}$ $\left(v_{\mathrm{Ar}-\mathrm{H}}\right), 2923 \mathrm{~m}\left(v_{\mathrm{C}-\mathrm{H}}\right), 1883 \mathrm{w}, 1639 \mathrm{~s}, 1569 \mathrm{~m}, 1475 \mathrm{~s}, 1427 \mathrm{vs}, 1335 \mathrm{~m}, 1252 \mathrm{~m}, 1186 \mathrm{~m}, 1048 \mathrm{~s}$, 997m, 846m, 731vs, 695s, 451s, 330m, 260s, 236m; Raman (glass capillary, $\mathrm{cm}^{-1}$ ) $v=$ $3049 \mathrm{~m}\left(v_{\mathrm{Ar}-\mathrm{H}}\right), 2929 \mathrm{~m}\left(v_{\mathrm{C}-\mathrm{H}}\right), 1602 \mathrm{~m}, 1572 \mathrm{~m}, 1446 \mathrm{w}, 1336 \mathrm{~s}, 1001 \mathrm{vs}, 657 \mathrm{~s}, 642 \mathrm{~m}, 584 \mathrm{~m}$, 257.8m; MS (ES+): $m / z(\%) 429.06(100)[\mathrm{M}-4 \times \mathrm{Ph},+\mathrm{ONa}], 621.16(10)$ [M-Ph]; HRMS (ES+): $m / z$ : Calcd. for $\mathrm{C}_{18} \mathrm{H}_{22} \mathrm{PSbONa}$ : 429.0344, found 429.0577, Calcd. for $\mathrm{C}_{36} \mathrm{H}_{37} \mathrm{PSb}$ : 621.1671 , found 621.1694 .

\section{Acknowledgements}

This work was financially supported by the EPSRC and COST actions CM0802 PhoSciNet and CM1302 SIPs. The authors would also like to thank the University of St Andrews NMR Service and to Mrs Caroline Horsburgh for running the MS spectra. MB thanks the School of Chemistry and EaStCHEM for support and for access to a computer cluster maintained by Dr. H. Früchtl.

Keywords: phosphorus · antimony $\cdot$ dative bond $\cdot$ peri-substitution $\cdot$ synthesis

\section{Graphical Abstract}

The strength of a dative phosphine-stiborane interaction increases with stepwise replacement of phenyl groups on antimony atom with chloride groups. As the Lewis acidity is increased in regular steps, essentially linear response is observed initially, however then a sudden change in the $\mathrm{P}-\mathrm{Sb}$ distance takes place during one particular step. This is consistent with a sudden 
switch from a non-bonding to a bonding interaction, i.e. a discrete rather than continuum response.

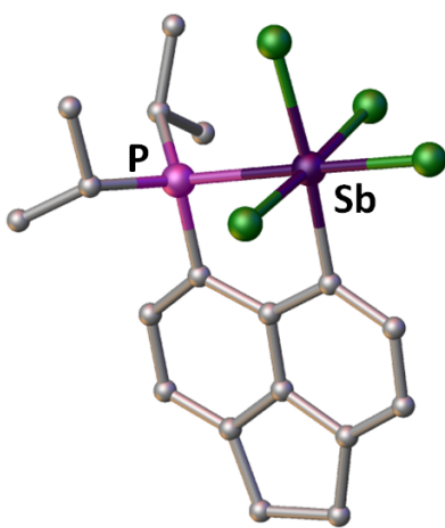

P-Sb $2.62 \AA$

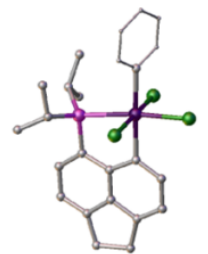

Increasing Lewis Acidity

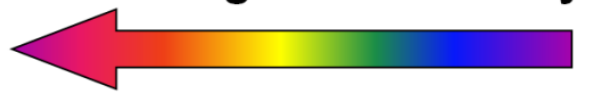

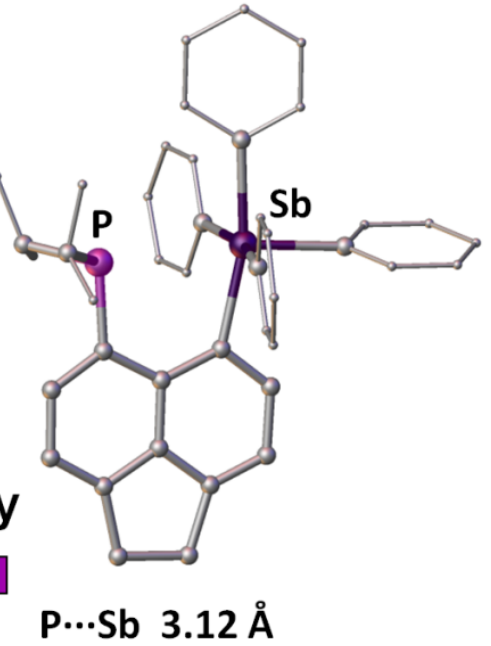

\section{References}

[1] a) Y. Wang, G. H. Robinson, Inorg. Chem. 2014, 53, 11815-11832; b) C. A. Dyker, G. Bertrand, Science 2008, 321, 1050-1051.

[2] a) D. Himmel, I. Krossing, A. Schnepf, Angew. Chem. Int. Ed. 2014, 53, 370-374; b)

D. Himmel, I. Krossing, A. Schnepf, Angew. Chem. Int. Ed. 2014, 53, 6047-6048; c)

G. Frenking, Angew. Chem. Int. Ed. Engl. 2014, 53, 6040-6046.

[3] a) S. S. Chitnis, N. Burford, Dalton Trans. 2015, 44, 17-29; b) J. Burt, W. Levason, G. Reid, Coord. Chem. Rev. 2014, 260, 65-115.

[4] a) P. Kilian, F. R. Knight, J. D. Woollins, Chem. Eur. J. 2011, 17, 2302-2328; b) P. Kilian, F. R. Knight, J. D. Woollins, Coord. Chem. Rev. 2011, 255, 1387-1413.

[5] a) H.-J. M. Gerhard Muller, Martin Winkler, Z. Naturforsch., B: Chem. Sci. 2001, 56b, 1155-1162; b) P. Wawrzyniak, A. L. Fuller, A. M. Z. Slawin, P. Kilian, Inorg. Chem. 2009, 48, 2500-2506.

[6] H. J. Breunig, M. Denker, K. H. Ebert, J. Chem. Soc., Chem. Commun. 1994, 875876.

[7] W. Clegg, M. R. J. Elsegood, V. Graham, N. C. Norman, N. L. Pickett, K. Tavakkoli, J. Chem. Soc., Dalton Trans. 1994, 1743-1751.

[8] H. J. Breunig, M. Denker, R. E. Schulz, E. Lork, Z. Anorg. Allg. Chem. 1998, 624, 8184.

[9] N. C. Norman, N. L. Pickett, Coord. Chem. Rev. 1995, 145, $27-54$. 
[10] S. S. Chitnis, N. Burford, R. McDonald, M. J. Ferguson, Inorg. Chem. 2014, 53, $5359-5372$.

[11] C. J. Carmalt, A. H. Cowley, R. D. Culp, R. A. Jones, S. Kamepalli, N. C. Norman, Inorg. Chem. 1997, 36, 2770-2776.

[12] T. Tokunaga, H. Seki, S. Yasuike, M. Ikoma, J. Kurita, K. Yamaguchi, Tetrahedron 2000, 56, 8833-8839.

[13] E. Hupf, E. Lork, S. Mebs, L. Chęcińska, J. Beckmann, Organometallics 2014, 33, 7247-7259.

[14] a) N. Burford, M. D'Eon, P. J. Ragogna, R. McDonald, M. J. Ferguson, Inorg. Chem. 2003, 43, 734-738; b) P. J. Ragogna, N. Burford, M. D'Eon, R. McDonald, Chem. Commun. 2003, 1052-1053.

[15] B. A. Chalmers, M. Bühl, K. S. Athukorala Arachchige, A. M. Z. Slawin, P. Kilian, J. Am. Chem. Soc. 2014, 136, 6247-6250.

[16] S. S. Batsanov, Inorg. Mater. 2001, 37, 871-885.

[17] a) I. R. Thomas, I. J. Bruno, J. C. Cole, C. F. Macrae, E. Pidcock, P. A. Wood, J. Appl. Crystallogr. 2010, 43, 362-366; b) F. H. Allen, Acta Crystallogr. Sect. B-Struct. Sci. 2002, 58, 380-388.

[18] W. Nakanishi, S. Hayashi, A. Sakaue, G. Ono, Y. Kawada, J. Am. Chem. Soc. 1998, $120,3635-3640$.

[19] B. A. Chalmers, K. S. Athukorala Arachchige, J. K. D. Prentis, F. R. Knight, P. Kilian, A. M. Z. Slawin, J. D. Woollins, Inorg. Chem. 2014, 53, 8795-8808.

[20] A. Haaland, Angew. Chem. Int. Ed. Engl. 1989, 28, 992-1007.

[21] Additional criterion to distinguish dative and "normal" bonds is used, which compares homolytic and heterolytic bond dissociation energies. The geometry of the backbone does not allow departure of the two peri-groups in $\mathrm{P}-\mathrm{Sb}$ dissociative reaction, therefore it is not possible to calculate $\mathrm{P}-\mathrm{Sb}$ bond rupture enthalpy directly in our compounds and hence compare (homolytic and heterolytic) P-Sb bond enthalpies.

[22] D. J. MacDonald, M. C. Jennings, K. E. Preuss, Acta Crystallographica Section C 2010, 66, m137-m140.

[23] M. J. Ray, A. M. Z. Slawin, M. Bühl, P. Kilian, Organometallics 2013, 32, 34813492.

[24] A. R. J. Genge, N. J. Hill, W. Levason, G. Reid, J. Chem. Soc., Dalton Trans. 2001, 1007-1012.

[25] R. R. Holmes, E. F. Bertaut, J. Am. Chem. Soc. 1958, 80, 2980-2983. 
[26] A. P. M. Robertson, N. Burford, R. McDonald, M. J. Ferguson, Angew. Chem. Int. Ed. 2014, 53, 3480-3483.

[27] a) F. B. Mallory, C. W. Mallory, K. E. Butler, M. B. Lewis, A. Q. Xia, E. D. Luzik, L. E. Fredenburgh, M. M. Ramanjulu, Q. N. Van, M. M. Francl, D. A. Freed, C. C. Wray, C. Hann, M. Nerz-Stormes, P. J. Carroll, L. E. Chirlian, J. Am. Chem. Soc. 2000, 122, 4108-4116; b) J.-C. Hierso, Chem. Rev. 2014, 114, 4838-4867.

[28] O. Kühl, in Phosphorus-31 NMR Spectroscopy: A Concise Introduction for the Synthetic Organic and Organometallic Chemist, Springer, Berlin, 2008, pp. 18-21.

[29] a) C. Lee, W. Yang, R. G. Parr, Physical Review B 1988, 37, 785-789; b) A. D. Becke, J. Chem. Phys. 1993, 98, 5648-5652.

[30] K. B. Wiberg, Tetrahedron 1968, 24, 1083-1096.

[31] The WBI is a measure for the covalent character of a bond and adopts values close to 1 and 2 for true single and double bonds, respectively.

[32] K. S. Athukorala Arachchige, P. Sanz Camacho, M. J. Ray, B. A. Chalmers, F. R. Knight, S. E. Ashbrook, M. Bühl, P. Kilian, A. M. Z. Slawin, J. D. Woollins, Organometallics 2014, 33, 2424-2433.

[33] A. E. Reed, L. A. Curtiss, F. Weinhold, Chem. Rev. 1988, 88, 899-926.

[34] M. Bühl, F. R. Knight, A. Kř́stková, I. Malkin Ondík, O. L. Malkina, R. A. M. Randall, A. M. Z. Slawin, J. D. Woollins, Angew. Chem. Int. Ed. 2013, 52, $2495-$ 2498.

[35] a) M. Yamashita, Y. Yamamoto, K.-y. Akiba, D. Hashizume, F. Iwasaki, N. Takagi, S. Nagase, J. Am. Chem. Soc. 2005, 127, 4354-4371; b) P. Kilian, A. M. Z. Slawin, J. D. Woollins, Chem. Commun. 2003, 1174-1175; c) T.-P. Lin, C. R. Wade, L. M. Pérez, F. P. Gabbaï, Angew. Chem. Int. Ed. 2010, 49, 6357-6360.

[36] B. A. Surgenor, M. Bühl, A. M. Z. Slawin, J. D. Woollins, P. Kilian, Angew. Chem. Int. Ed. 2012, 51, 10150-10153.

[37] W. L. F. Armarego, C. L. L. Chai, Purification of Laboratory Chemicals (6th Edition), 6th ed., Elsevier, Burlington.

[38] a) W. A. Herrmann, H. H. Karsch, in Synthetic Methods of Organometallic and Inorganic Chemistry Vol 3: Phosphorus, Arsenic, Antimony and Bismuth, Vol. 3, Thieme, New York, 1996, pp. 188-210; b) A. J. Banister, L. F. Moore, J. Chem. Soc. A 1968, 1137-1138; c) T. Tunde Bamgboye, M. J. Begley, D. Bryan Sowerby, J. Organomet. Chem. 1989, 362, 77-85; d) W. J. Lile, R. C. Menzies, J. Chem. Soc. 1950, 617-621; e) M. Fujiwara, M. Tanaka, A. Baba, H. Ando, Y. Souma, J. 
Organomet. Chem. 1996, 508, 49-52; f) M. Ates, H. J. Breunig, A. Soltani-Neshan, M. Tegeler, Z. Naturforsch., B: Chem. Sci. 1986, 41b, 321-236. 